\title{
Dynamic Modelling and Performance Optimization-Based Sliding Mode Control of Process Drying in a Convective Tunnel Dryer
}

Hatem Oueslati, Research and Technology Center of Energy, Tunisia

Salah Ben Mabrouk, Research and Technology Center of Energy, Tunisia

Abdelkader Mami, Faculty of Sciences of Tunis, Tunisia

\begin{abstract}
In this work, the researchers thoroughly investigate the use of sliding mode control for nonlinear systems, especially its application for the control of dryer designed for drying food products. A dynamic model of the drying process has been developed, and experimental measurements presented in this paper are established for different values of drying air temperature and drying air velocity. Two scenario of sliding mode control applied to the hybrid tunnel dryer have been assessed through simulations. At first, a nonlinear sliding mode control with first order sliding surface was tested. In front of the insufficient performance of this control in terms of the presence of chattering phenomenon and static error, it was decided to apply a nonlinear sliding mode control with PI sliding surface. Simulation results show that this latter control approach can obtain excellent control performance with no chattering problem, reduction of static error, and a good tracking of trajectory.
\end{abstract}

\section{KEYWORDS}

Moisture Content, PI Sliding Surface, Sliding Mode Control, Temperature, Tunnel Dryer

\section{INTRODUCTION}

The practice of drying is one of the oldest techniques used in various fields of industry, while many studies have dealt to the exploration of different designs and types of dryers. Low temperature drying of thin and fixed film products is important in the food industry. Moist agricultural products require short drying with ventilation (Mercier et al. 2014, Paul et al. 2008). While other wetter products can be dried for long periods with conditions close to the ambient environment, they are very economical in terms of energy (Jekayinfa, \& Bamgboye, 2006, Nawshad \& Michael, 2013, Ehsan \& Nikbakhsh, 2018, Isdore, Agnes, \& Benedict, 2018, Luciandra et al. 2018).

Furthermore, the drying of agro-food products is done in sophisticated dryers, ensuring a rational implementation of the operation (Amer, Hossain \& Gottschalk, 2010), from the most used industrial dryers are convective tunnel dryers.

Most of these dryers operate in forced convective mode where the main thermal energy generator can be conventional (gas or fuel burner), solar or combined. These dryers are equipped with fans for air circulation and a regulation system to achieve the desired performance (Bala et al. 2003, Salah \& Ali, 1994, Hossain \& Bala, 2007). Food dehydration is an energy intensive process in which energy cost 
constitutes a major portion of drying cost. Optimal operation of dryer is one of the feasible methods for energy saving. Tunnel dryer is widely used for dehydrating fruits and vegetables specially in Mediterranean countries. The operation of hybrid solar dryers is ensured by two energy sources, solar and conventional, which allows them a continuous operating mode whatever the weather conditions (Amer, Hossain \& Gottschalk, 2010, Vidaña, Lagunas \& Ramírez, 2013, Mohajer et al. 2013, Hatem, Salah \& Abdelkader, 2014).

Before any sizing, identification or simulation application, the modelling of the drying processes seems essential. In the literature (Dinghua, Meibao \& Haili, 2013, Salah, Elaid, \& Hatem, 2012, Khatchatourian, Vielmo, \& Bortolaia' 2013, Naghavi, Moheb \& Ziaei-rad, 2010) several models are presented which models the different drying techniques and phenomena. The complexity of the drying phenomenon requires the choice of a well-determined modelling technique. In this work we will use the models developed in previous work (Hatem, Salah \& Abdelkader, 2014) based on the bond graph methodology. This modelling tool determine the dynamic mathematical model, most often based on ODE equations (Karnopp, Margolis \& Rosenberg, 1990, Hatem, Salah, and Abdelkader, 2014, Pichardo \&. Delgado, 2003).

To obtain the desired product quality, it would be interesting to optimize industrial drying processes. The area of control of drying process has not been sufficiently studied due to the fact that the dynamic drying models developed tend to be complex because they include systems of coupled and nonlinear equations. The drying rate and the phenomena of heat and mass transfer are well described by these equations.

Likewise, the measurement of the moisture content of agricultural products during drying in industrial or semi-industrial dryers is often difficult for several reasons of instrumentation and location of appropriate sensors (Fionn et al.,2014).

To remedy the problems encountered in the dryers to optimize and improve the performance of the drying processes, different control techniques developed can be applied.

A traditional control approach has been used by many researchers to control fluidized bed dryers (Temple \& van Boxtel,2000, Abdel-Jabbar, Jumah \& Al-Haj Ali, 2005, Atthajariyakul \& Leephakpreeda, 2006, Villegas et al. 2009, Aghbashlo et al. 2014, Vieira et al. 2019; Van Engeland et al. 2019). Another model-based control approach has not been widely used by researchers in the field of dryer control until now (Robert et al. 2019, Andreas et al. 2018; Lars et al. 2017).

The literature is very poor in terms of optimization and control equipment. When we try to improve a drying process, different targets can be set according to the drying method, the type of product or application at industrial level.

Currently the control of heat and mass transfer in the dryers of agro-food products is important to preserve product quality like colour and flavour (Pkez-Correa et al., 1998; Gianini et al., 2010). The main challenge for the engineer is to design optimal dryers, which provide a good product quality. Reducing the drying time allowing increased productivity, may be a priority. It can also act to improve the quality of the final product or to reduce manufacturing costs including restricting energy intake. Control of the drying process can also be effective in reducing the influence of external disturbances (Rodriguez, Vasseur \& Courtois, 1996, Musen, Jianxiong \& Wansheng, 2014, Maya et al., 2014).

The first part of this work presented in this paper focuses on:

- The description of the system in detail as well as its design and operation mode.

- The mathematical model representative of the drying operation.

- Analysis of experimental results established on the drying of tomato slices.

In the second part, we study the application of the sliding mode control to the dryer; this method is designed for a class of nonlinear dynamic systems to tackle the problems with model uncertainties, parameter fluctuations and external disturbances (Jalel, Ahmed \& Sundarapandian, 2018, Sana, B \& Anis, 2018). The sliding mode control (SMC) is a type of robust control design that plays an important 
role in the class of variable structure control systems (VSCS) (Utkin, 1977). The technique of higher order sliding mode control can be used (İlyas, 2006, Lokukaluge \& Soares, 2012, Mounir et al. 2018). The presence of a static error and the phenomenon of chattering might be eliminated by adding an integral action at the sliding surface (Marcel \& Ron, 2014).

\section{THE DRYER AND ITS MODEL}

A solar hybrid tunnel dryer with back-up system is used in the drying operation as shown in Figure 1. This system has been designed to dry slices of wet agricultural products placed in trays and oriented to a hot air flow. The moist air in the chamber will be completely exhausted to the outside through the chimney due to the pressure difference between the chamber and the outside in natural operating mode (Hatem, Salah \& Abdelkader, 2014, Hatem, Salah \& Abdelkader 2012).

Figure 1.

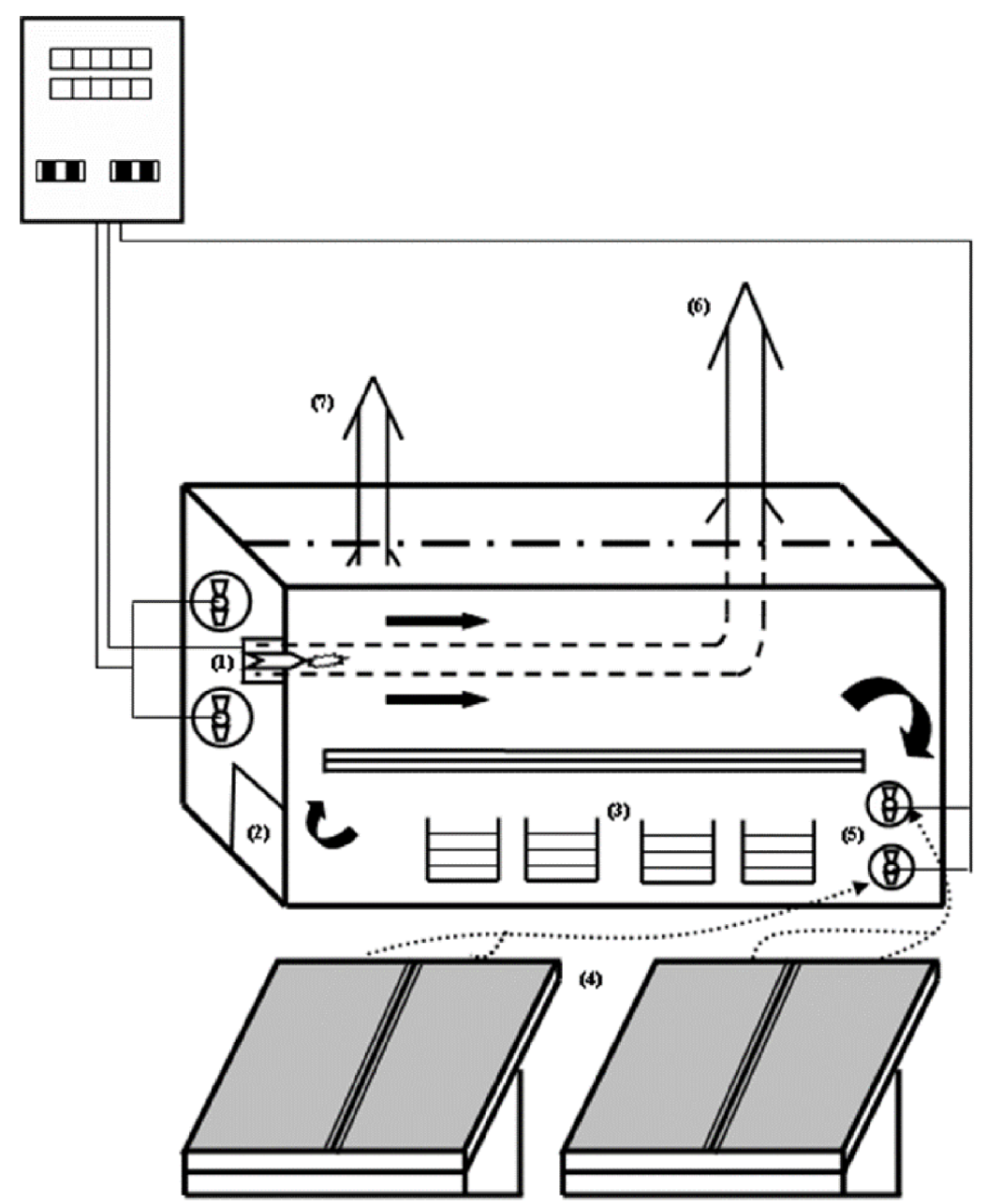


The mathematical model of the system has been developed in previous work (Hatem, Salah \& Abdelkader, 2014), where the detailed equations for the energy flow balance are:

- energy balance equation of the product

$$
C_{p r} \frac{d T_{p r}}{d t}=h_{c 1}\left(T_{h a}-T_{p r}\right) A_{p r}-\left(h_{c 2}+h_{e v a p}\right)\left(T_{p r}-T_{c h}\right) A_{p r}
$$

- $\quad$ energy balance equation of the moist air in the drying chamber

$$
C_{c h} \frac{d T_{c h}}{d t}=\left(h_{c 2}+h_{\text {evap }}\right)\left(T_{p r}-T_{c h}\right) A_{p r}-h_{c 3}\left(T_{c h}-T_{w a}\right) A_{w a}-c_{d} A_{e} \sqrt{2 g \Delta H} \Delta P
$$

- energy balance equation of the wall of the drying chamber

$$
C_{w a} \frac{d T_{w a}}{d t}=h_{c 3}\left(T_{c h}-T_{p r}\right) A_{w a}-h_{d}\left(T_{w a}-T_{e x}\right) A_{w a}
$$

The rate of change in moisture content when drying a product estimated at a thin layer of water can be written as the drying equation (Lewis, 1921):

$$
\left(-\frac{d M}{d t}\right)=k\left(M-M_{e}\right)
$$

Where $k$ is the drying constant which depends on the temperature of the moist air:

$$
k=0.00719 \exp \left(-\frac{130.64}{T c h}\right)
$$

$M$ and $M e$ are respectively the instantaneous moisture content and the equilibrium moisture content of the wet agricultural product, $M e$ was predicted from the GAB model by using the following equations (Lopez et al., 2000):

$$
M e=\frac{W_{m} C K a_{w}}{\left(1-K a_{w}\right)\left[1+(C-1) K a_{w}\right]}
$$

Where $W m, C$ and $K$ are parameters related with air temperature by the following expressions:

$$
W_{m}=0.0014254 \exp \left(\frac{1193.2}{T_{k}}\right)
$$




$$
\begin{aligned}
& C=0.5923841 \exp \left(\frac{1072.5}{T_{k}}\right) \\
& K=1.00779919 \exp \left(-\frac{43.146}{T_{k}}\right)
\end{aligned}
$$

$T_{k}$ is air absolute temperature $(\mathrm{K})$ and $a_{w}$ is the water activity.

\section{RESULTS AND ANALYSIS}

We consider a thin layer of tomato placed in the trays inside the drying chamber. This layer of product is dried by a flow of hot air whose physical properties are known. The calculations were carried out using the parameters of the system (Table 1) and this for the analysis of the thermal performance of the studied tunnel dryer.

It is considered that the air velocity is constant $2 \mathrm{~m} / \mathrm{s}$ and the temperature of the drying air is varied. The temperature profile of the product, moist air and inner wall have been illustrated in Figures 2,3 and 4, where each increase until that which stabilizes at a temperature than that of the drying air.

In addition, we illustrate the moisture content variation of the product under the same conditions in Figure 5. The drying time is shortened with increasing temperature, which is explained by the increased potential for exchange between the drying air and the product, thus promoting the evaporation of water from the tomatoes. The predicted values of the different variables agree well with the experimental values. Goodness of fit was determined using Root Mean Square Errors-RMSE (Table 2).

\section{SLIDING MODE CONTROL}

The expectations from the control of the tunnel dryer studied are numerous:

- An aesthetic and nutritious quality of the desired dried product, whatever the disturbances encountered during the drying operation.

- Stability of the drying operation.

- Optimization of the performance of the drying process

- Optimum energy efficiency with minimum cost.

- A secure system.

In this paper, the developed model of the tunnel dryer based on ODE equations is relevant for examining control strategies. This will be realized by applying the slide mode control strategy.

The nonlinear dynamical model of the dryer is deduced from the representative energy balance equations $(1,2,3)$ and the drying rate equation (4) presented by the following state space model as: 
Table 1. Numerical Value used in simulation

\begin{tabular}{|c|c|c|c|}
\hline Parameters & Values & Parameters & Values \\
\hline $\begin{array}{l}A_{p r} \\
A_{w a} \\
A_{e} \\
a_{w} \\
C_{p, p r} \\
C_{p, c h} \\
C_{p, w a} \\
c_{d} \\
D \\
g d_{i} \\
m_{p r}\end{array}$ & $\begin{array}{l}0.5\left(\mathrm{~m}^{2}\right) \\
3\left(\mathrm{~m}^{2}\right) \\
0.00785\left(\mathrm{~m}^{2}\right) \\
0.2 \\
4180\left(\mathrm{~J} / \mathrm{kg}^{\circ} \mathrm{C}\right) \\
1006\left(\mathrm{~J} / \mathrm{kg}^{\circ} \mathrm{C}\right) \\
860\left(\mathrm{~J} / \mathrm{kg}^{\circ} \mathrm{C}\right) \\
0.6 \\
0.66(\mathrm{~m}) \\
9.8\left(\mathrm{~ms}^{-2}\right) \\
0.15(\mathrm{~m}) \\
10(\mathrm{~kg})\end{array}$ & $\begin{array}{l}M_{i n} \\
\rho_{c h} \\
\rho_{w a} \\
\lambda_{a} \\
\lambda_{i} \\
0 \\
\gamma_{c h} \\
\gamma_{\text {ex }} \\
k_{s} \\
\alpha \\
k_{p} \\
k_{i}\end{array}$ & $\begin{array}{l}16.14 \mathrm{~kg} / \mathrm{kg}^{-1}(\mathrm{db}) \\
1.16\left(\mathrm{~kg} / \mathrm{m}^{3}\right) \\
2700\left(\mathrm{~kg} / \mathrm{m}^{3}\right) \\
0.0262\left(\mathrm{~W} / \mathrm{m}^{\circ} \mathrm{C}\right) \\
0.022\left(\mathrm{~W} / \mathrm{m}^{\circ} \mathrm{C}\right) \\
2.10^{-5}\left(\mathrm{~m}^{2} / \mathrm{s}\right) \\
0.66(\mathrm{dec}) \\
0.35(\mathrm{dec}) \\
50 \\
0.9 \\
5 \\
0.1\end{array}$ \\
\hline
\end{tabular}

Figure 2.

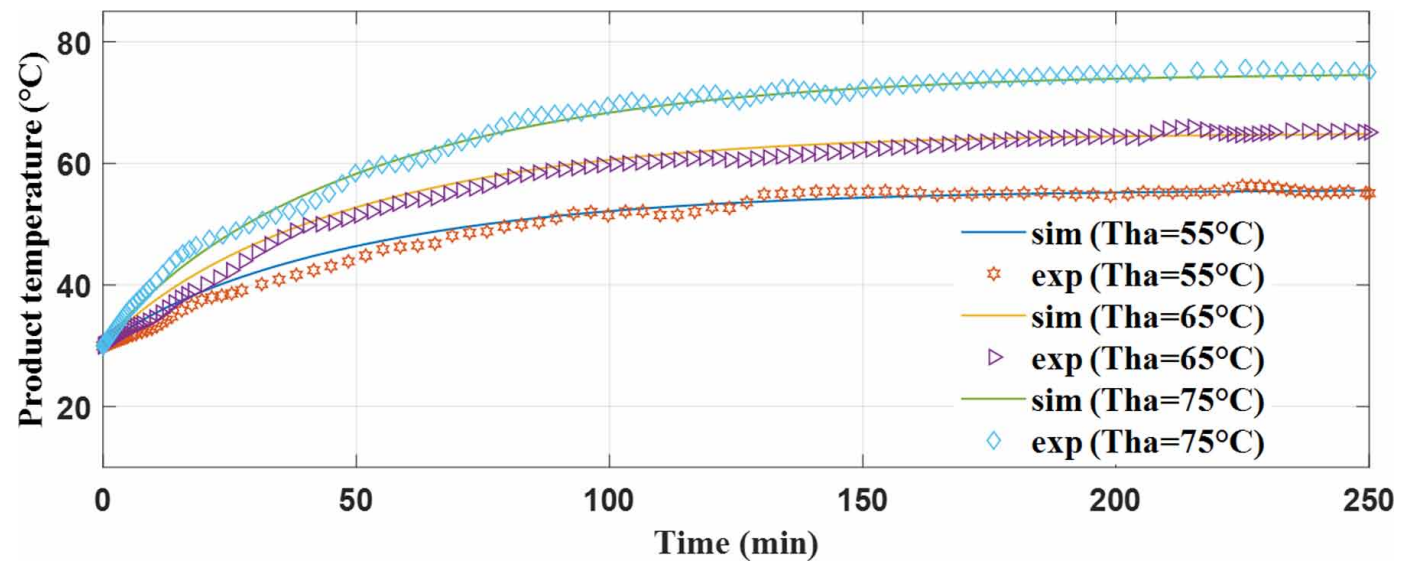

Figure 3.

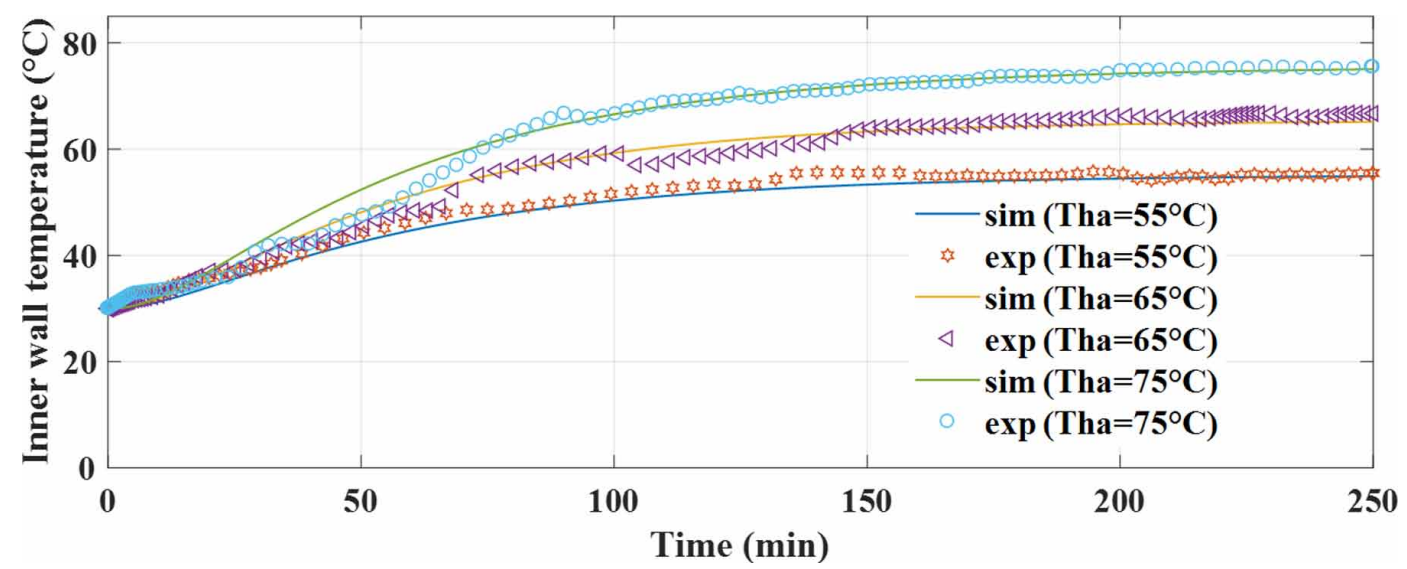


Figure 4.

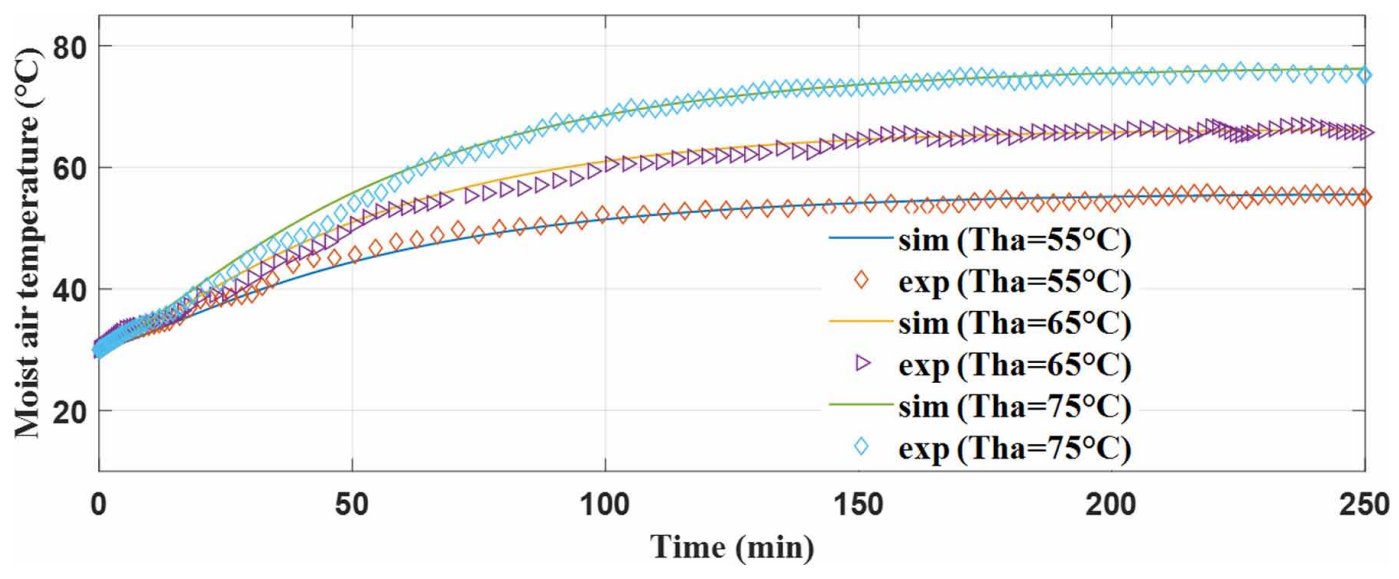

Figure 5.

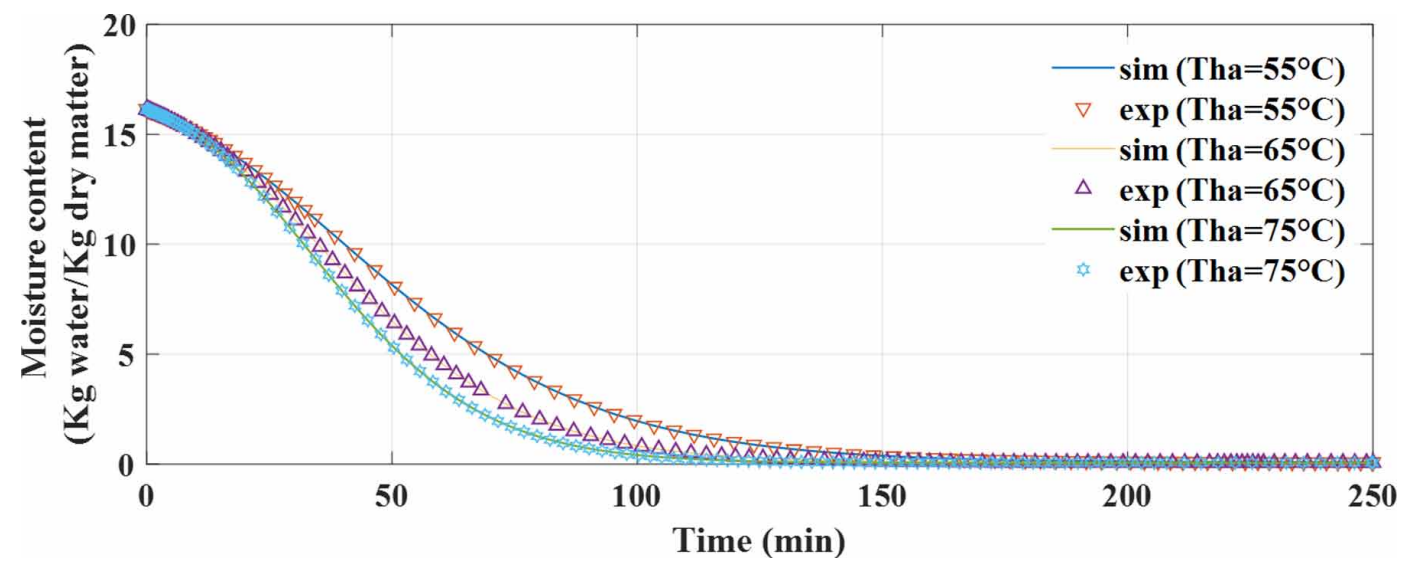

Table 2. The values of RMSE

\begin{tabular}{|l|l|l|l|}
\hline \multirow{2}{*}{ Variables } & \multicolumn{2}{|l|}{ Variation of drying air temperature for $U a=\mathbf{2 m} / \mathbf{s}$} \\
\cline { 2 - 4 } & $\mathbf{T a c}=\mathbf{5 5}^{\circ} \mathbf{C}$ & $\mathbf{T a c}=\mathbf{6 5}^{\circ} \mathbf{C}$ & $\mathbf{T a c}^{\circ} \mathbf{7 5}^{\circ} \mathbf{C}$ \\
\hline Product temperature & 1.1249 & 1.1996 & 0.8625 \\
\hline Moist air temperature & 0.8034 & 0.9499 & 0.8665 \\
\hline Inner wall temperature & 1.3539 & 1.4301 & 1.7368 \\
\hline Moisture content & $3.9665 .10^{-4}$ & $4.1778 .10^{-4}$ & $4.7045 .10^{-4}$ \\
\hline
\end{tabular}




$$
\left\{\begin{array}{c}
\frac{d T_{p r}}{d t}=\frac{1}{C_{p r}}\left[h_{c 1}\left(T_{h a}-T_{p r}\right) A_{p r}-\left(h_{c 2}+h_{e v a p}\right)\left(T_{p r}-T_{c h}\right) A_{p r}\right] \\
\frac{d T_{c h}}{d t}=\frac{1}{C_{c h}}\left[\left(h_{c 2}+h_{e v a p}\right)\left(T_{p r}-T_{c h}\right) A_{p r}-h_{c 3}\left(T_{c h}-T_{w a}\right) A_{w a}-c_{d} A_{e} \sqrt{2 g \Delta H} \Delta P\right] \\
\frac{d T_{w a}}{d t}=\frac{1}{C_{w a}}\left[h_{c 3}\left(T_{c h}-T_{p r}\right) A_{w a}-h_{d}\left(T_{w a}-T_{e x}\right) A_{w a}\right] \\
\frac{d M}{d t}=-k(M-M e)
\end{array}\right.
$$

Where: $X(t)=\left[x_{1}(t), x_{2}(t), x_{3}(t), x_{4}(t)\right]^{T}=\left[T_{p r}, T_{c h}, T_{w a}, M\right]^{T}$ is the state vector and $u(t)=T_{h a}$ is the control input vector.

\section{Background on Sliding Mode Control}

Milestones for sliding mode control design can be described, by using an equivalent control concept, as follow:

The general approach is first to select a sliding surface, $\mathrm{S}(\mathrm{x})$, to set the desired dynamics of the controlled system. Then to design a control law leading the state trajectory on the sliding surface in a finite time and forcing it to stay on this surface (Hung, Gao \& Hung, 1993). if the "sliding mode" is reached, the trajectory remains on the switching surface. It's expressed by:

$$
S(x)=0 \text { and } \dot{S}(x)=0
$$

The attractiveness of the surface $S$ can then be summarized by the equation (12) known as the reaching condition (Slotine \& Li, 1991):

$$
S \dot{S}<0
$$

The control law is proposed in this way:

$$
u=u_{s}+u_{e q}
$$

Where, $u_{e q}$ and $u_{s}$ are the signals for equivalent control and switching control, respectively.

To obtain the control requirements, a reaching condition (Gao \& Hung, 1993) (power rate reaching law) is designed as:

$$
S=-k_{s}|S|^{\alpha} \operatorname{sgn}(S)
$$

Where $0<\alpha\left\langle 1\right.$ and $\left.k_{s}\right\rangle$ (control gain).

The finite reaching time required to reach the sliding surface, from an initial condition is given by: 
$T=\frac{1}{(1-\alpha) k} S_{0}^{(1-\alpha)}$

The advantage of this form is that the switching time is over. In addition, it reduces the effect of the chattering phenomenon.

\section{Simulation Results}

Simulation result has been made using MATLAB software under this condition: an average airdrying speed equal to $3 \mathrm{~m} / \mathrm{s}$ and the ambient air temperature is $25^{\circ} \mathrm{C}$. The product to be dried is very wet, these physical properties are the same as that of water such as tomatoes, grapes, and beets ... numerical calculations are established based on numerical values in the table1.

The desired trajectory of system output has been designed with variation of the setpoint as follows:

$$
\left\{\begin{array}{c}
x_{1 d}(t)=25+25(1-\exp (0.002 t)) \text { if } t<7500 s \\
x_{1 d}(t)=50+20(1-\exp (0.002(t-7500))) \text { if } t>7500 s
\end{array}\right.
$$

\section{$1^{\text {st }}$ Scenario}

Typically, the sliding surface is constructed by linear combination of the errors variables that are defined as differences between the state variables and their references (desired).

$S$ is defined as:

$$
S(x)=e(t)
$$

Where $\mathrm{e}(\mathrm{t})$ is the tracking error and defined as:

$$
e(t)=x(t)-x_{d}(t)
$$

Which $x d(t)$ is the desired trajectory and $x(t)$ the controlled state variable.

The objective is to regulate the product temperature in the dryer. So,

$$
S(x)=x_{1}(t)-x_{1 d}(t)
$$

The equivalent control is calculated as follow:

Considering the condition of the sliding mode: $\dot{S}(x)=0$, we obtain the equivalent control law:

$$
u_{e q}(t)=\frac{1}{h_{c 1}}\left[\dot{x}_{1 d}(t) \cdot \frac{C_{p r}}{A_{p r}}+\left(h_{c 2}+h_{\text {evap }}\right) \cdot\left(x_{1}(t)-x_{2}(t)\right)\right]+x_{1}(t)
$$


The sliding mode control law Eq. (13) is proven to make the closed-loop control system asymptotically stable by introducing the positive definite Lyapunov function:

$V=\frac{1}{2} S^{2}$

The time derivative of Eq. (21) is:

$$
\left\{\begin{array}{c}
\dot{V}=S \dot{S}=S\left(\dot{x}_{1}-\dot{x}_{1 d}\right) \\
\dot{V}=S\left(\frac{1}{C_{p r}}\left[h_{c 1}\left(u-x_{1}\right) A_{p r}-\left(h_{c 2}+h_{\text {evap }}\right)\left(x_{1}-x_{2}\right) A_{p r}\right]-\dot{x}_{1 d}\right) \\
\dot{V}=S\left(-k_{s}|S|^{\alpha} \operatorname{sgn}(S)\right) \\
\dot{V}=-k_{s}|S|^{\alpha+1}
\end{array}\right.
$$

Therefore, the control law Eq. (13) achieves the control objective (i.e., $S(t) \rightarrow 0$ ast $\rightarrow \infty$ ) Figures 6, 7, 8 and 9 illustrate the evolution of the four state variables; in which Figure 6 shows a good pursuit of the product temperature to the desired value while a phenomenon of chattering of 6 minutes duration appears during this evolution.

Figure 6 .

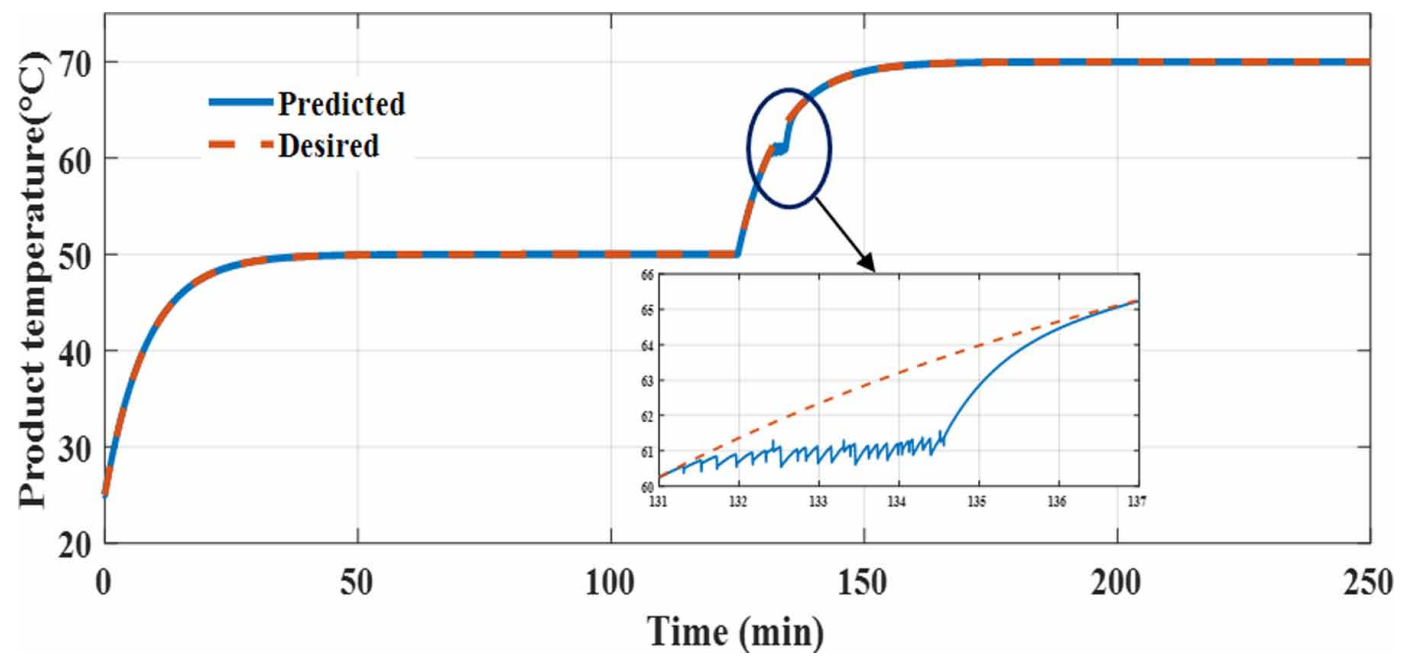

The moist air temperature and the temperature of the inner wall are shown in Figures 7 and 8, we see that these two curves have the same trajectory as the temperature of the product and that they converge towards the same operating point with a slight static error $\left(1.5 \%\left(1^{\circ} \mathrm{C}\right)\right.$ for the temperature of the internal air and $3 \%\left(2{ }^{\circ} \mathrm{C}\right)$ for the temperature of the inner wall $)$, and a phenomenon of chattering 
Figure 7.

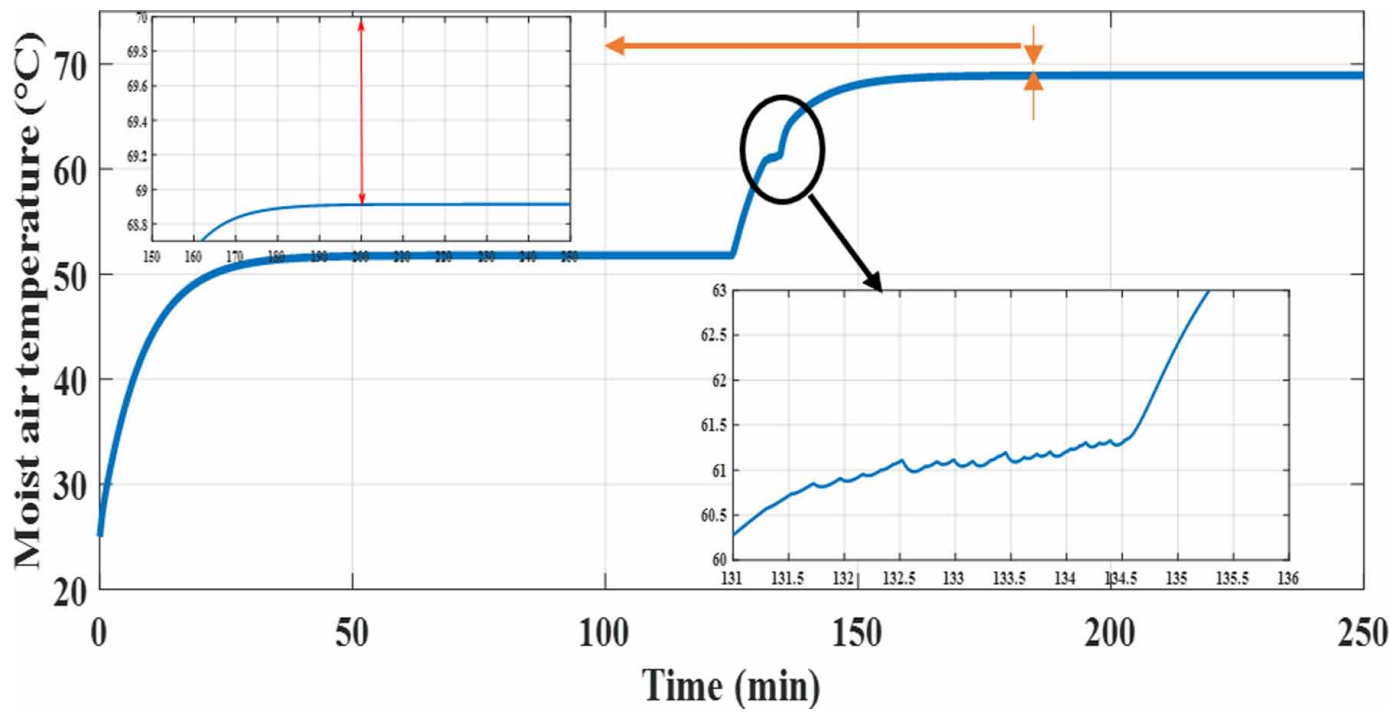

Figure 8 .

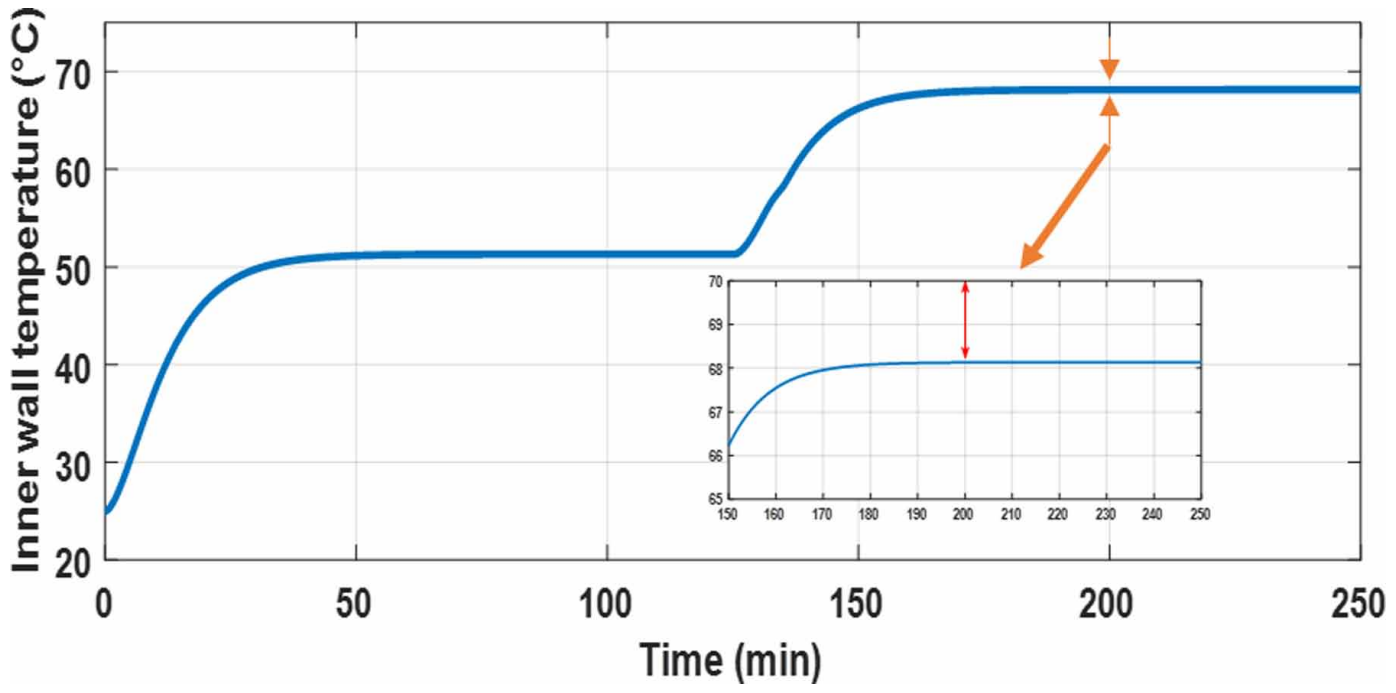

of 5 minutes duration appears during the change of the temperature of the internal air represented by the Figure 7.

The evolution of the control law and the sliding surface are shown respectively in Figures 10 and 11. This proves that the sliding mode control allows the outputs converge to their reference values resulting components of the sliding surface to zero. So, we must think of optimizing this control technique to avoid problems in practice. 
Figure 9 .

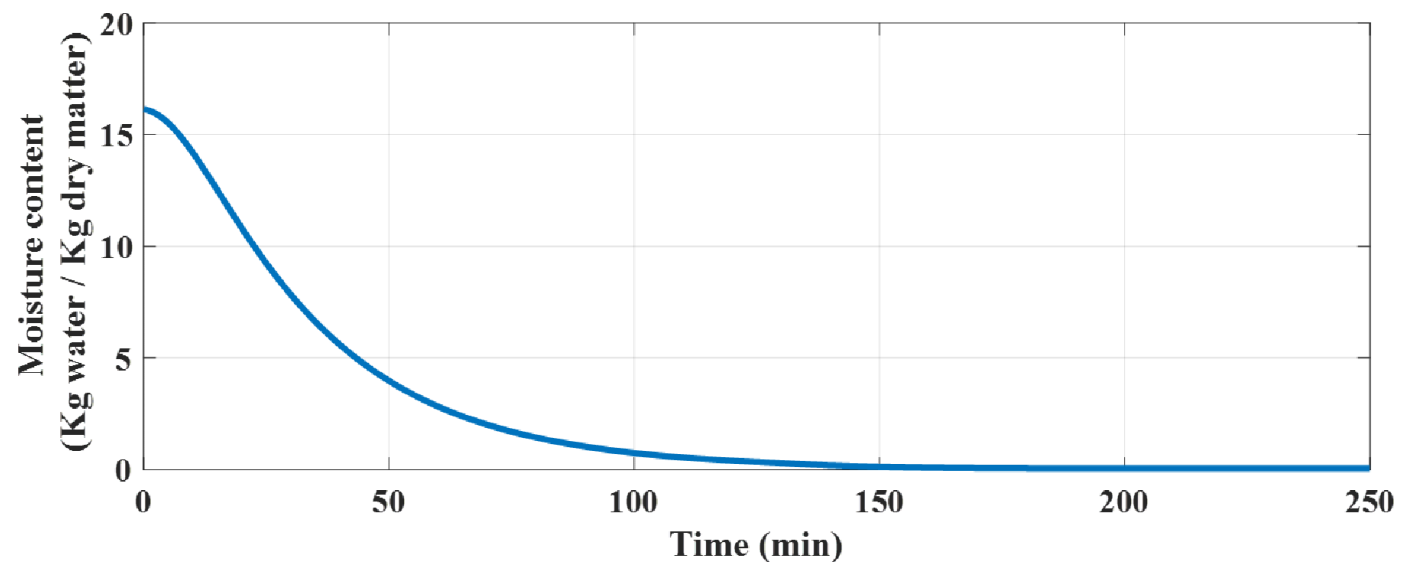

\section{$2^{\text {nd }}$ Scenario}

The disadvantage of sliding mode control is the appearance of the chattering phenomenon; this characteristic is proved in simulation. To address this problem, the $\operatorname{sgn}(S)$ function can be replaced by other functions such as $\operatorname{Sat}(S)$ and $\operatorname{tangh}(S)$ (Emelyanov, Korovin \& Levantovsk, 1986, Floquet, Barbot, \& Perruquetti, 2003) but a drop in system performance is observed with the persistence of the chattering, in this case the technique of higher order sliding mode control can be used (Marco, Leonid \& Arie, 2011, Zolezzi, 2004, Delprat \& Ferreira, 2012). The presence of a static error and the phenomenon of chattering might be eliminated by adding an integral action at the sliding surface (Salah, Franck \& Alain, 2007, Hebertt, 2003).

Then a sliding proportional + integral (PI) surface in the space of error can be defined as:

$S(t)=k_{p} e(t)+k_{i} \int_{0}^{t} e(\tau) d \tau$

Where the coefficients $k_{p}, k_{i} \in R^{+}$and $e(t)$ is the tracking error and defined as defined by Eq (18).

Figure 10.

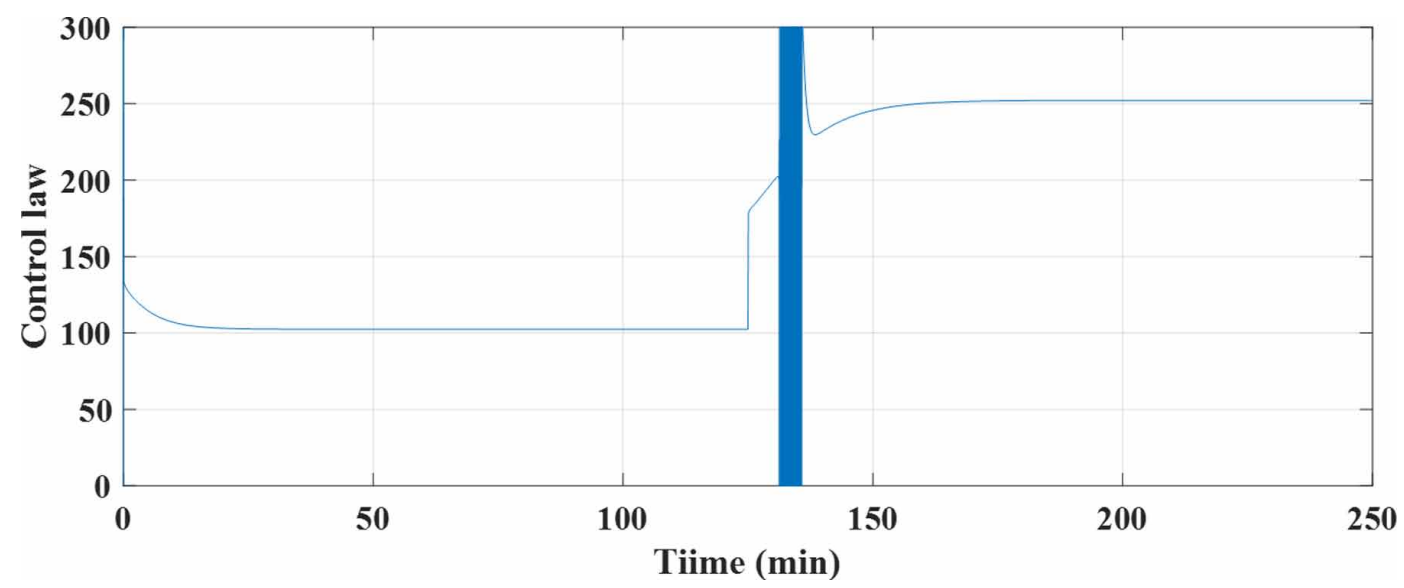


Figure 11.

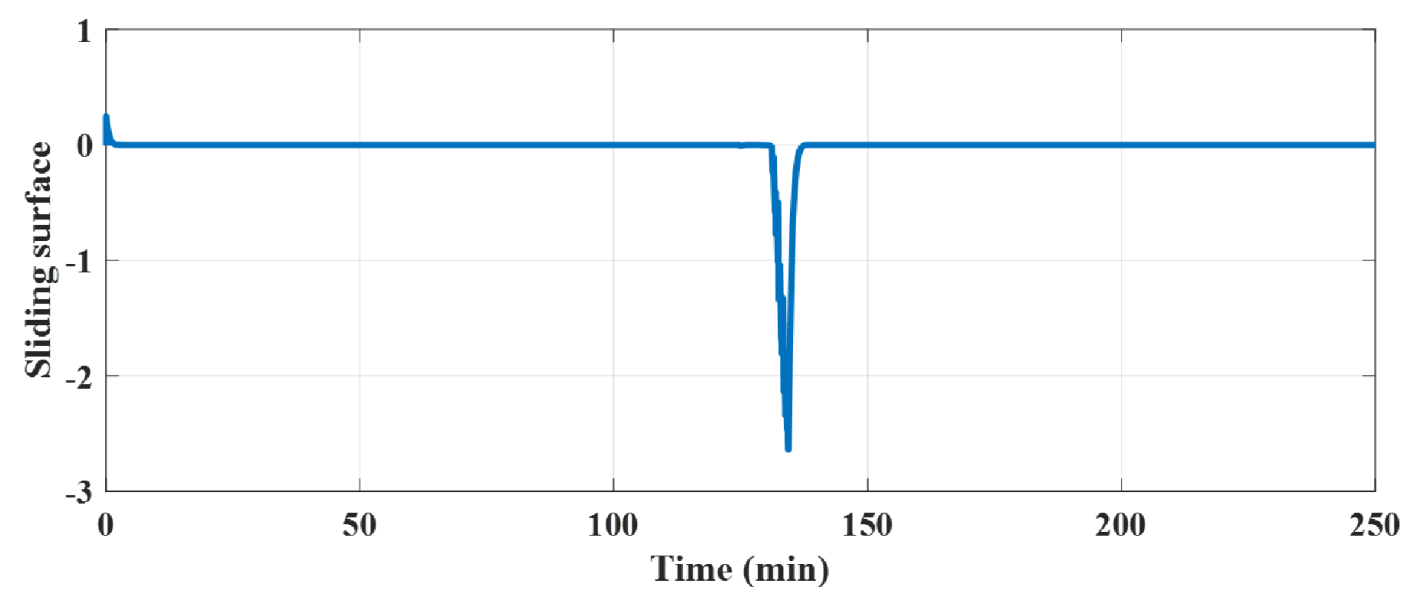

The derivative of the sliding surface defined by Eq (23) can be given as:

$$
\dot{S}(t)=k_{p} \dot{e}(t)+k_{i} e(t)
$$

to calculate the equivalent control, we use the relation $\dot{S}(x)=0$ which gives:

$$
u_{e q}(t)=\frac{1}{h_{c 1}}\left[\left(\dot{x}_{1 d}(t)-k_{i} e(t)\right) \cdot \frac{C_{p r}}{A_{p r} k_{p}}+\left(h_{c 2}+h_{\text {evap }}\right) \cdot\left(x_{1}(t)-x_{2}(t)\right)\right]+x_{1}(t)
$$

The stability for this controller can be proved in the same method to the first one. The improvement of these results was established by applying the second scenario of the proposed control law in this paper.

Figures 12, 13, 14 and 15 illustrate the evolution of the four state variables and Figure 12 shows a good pursuit of the product temperature to the desired value with the disappearance of the chattering phenomenon.

The variation of internal air and inner wall temperature are illustrated in Figures 13 and 14. We note that although the phenomena of chattering and static error are eliminated in the evolution of the variable temperature of the internal air. More, static error was reduced to $0.5 \%$ instead of $3 \%$ for the evolution variable temperature of the inner wall as shown in Figure 14.

The evolution of the control law and the sliding surface are shown respectively in Figures 16 and 17. This proves that the sliding mode control allows the outputs converge to their reference values resulting components of the sliding surface to zero. Similarly, we note the absence of the phenomenon of chattering. It is noticeable that the proposed method has a better performance compared to the previous one.

\section{Robustness Test}

We tested the robustness of the control law established by parametric variations. We carried out a variation of $50 \%$ on the velocity of drying air.

Simulation results made in the presence of the parametric variations are shown in Figures 18, 19,20 and 21 . 
International Journal of System Dynamics Applications

Volume 10 •Issue 4

Figure 12.

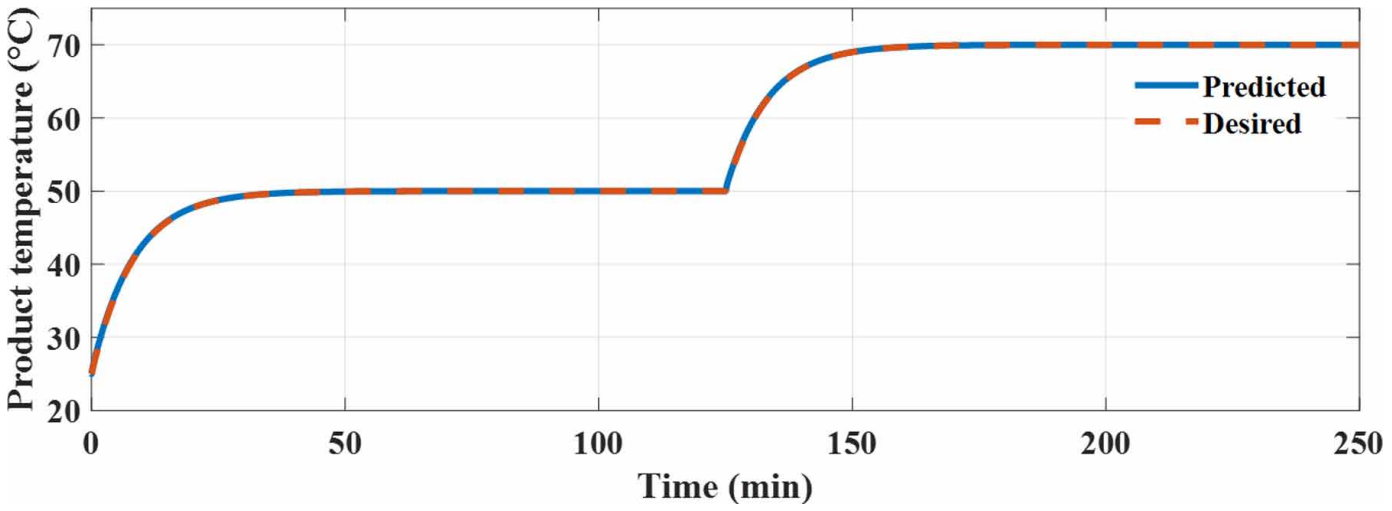

Figure 13.

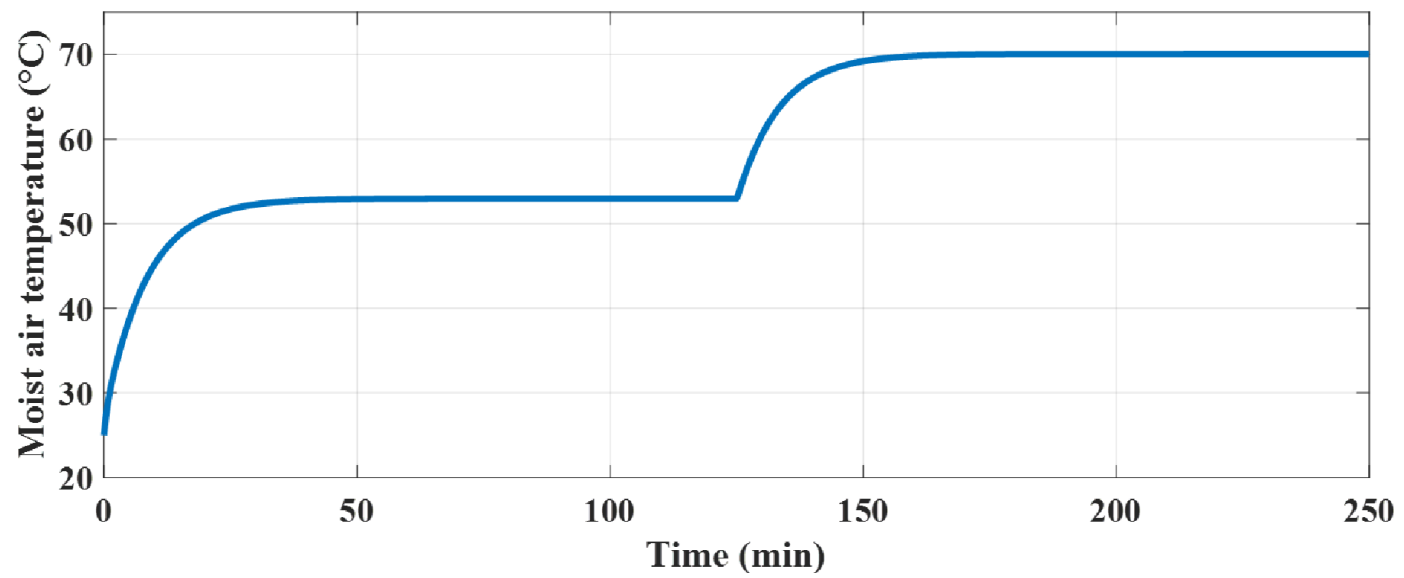

Figure 14.

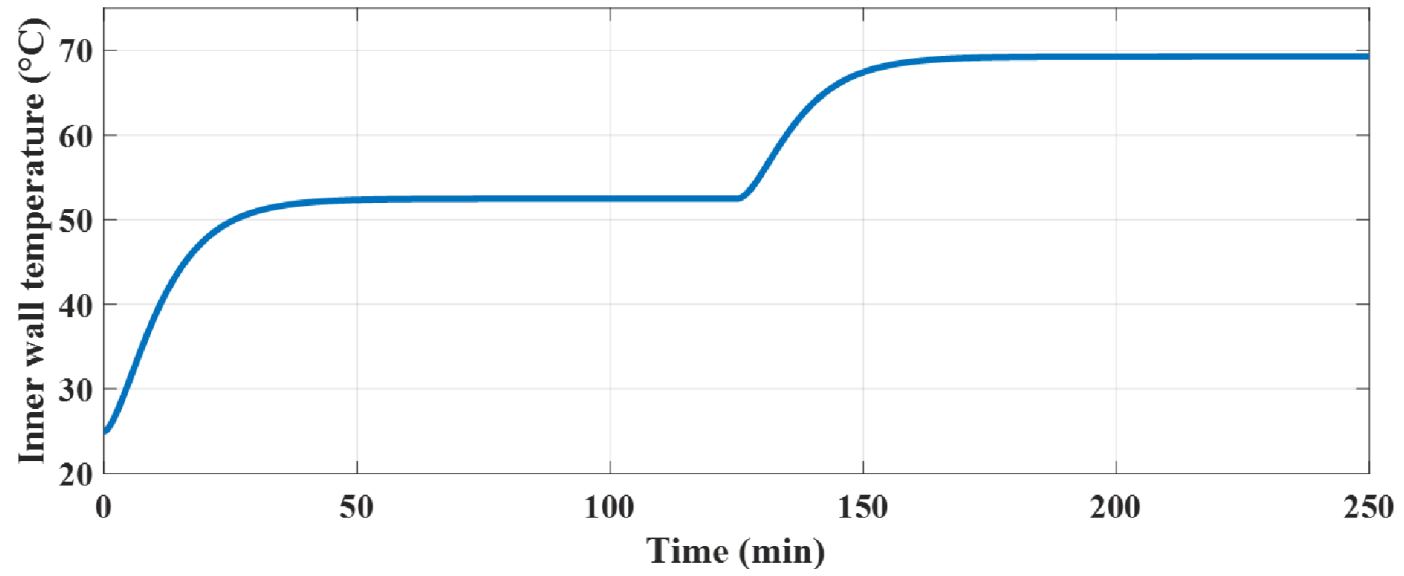


Figure 15.

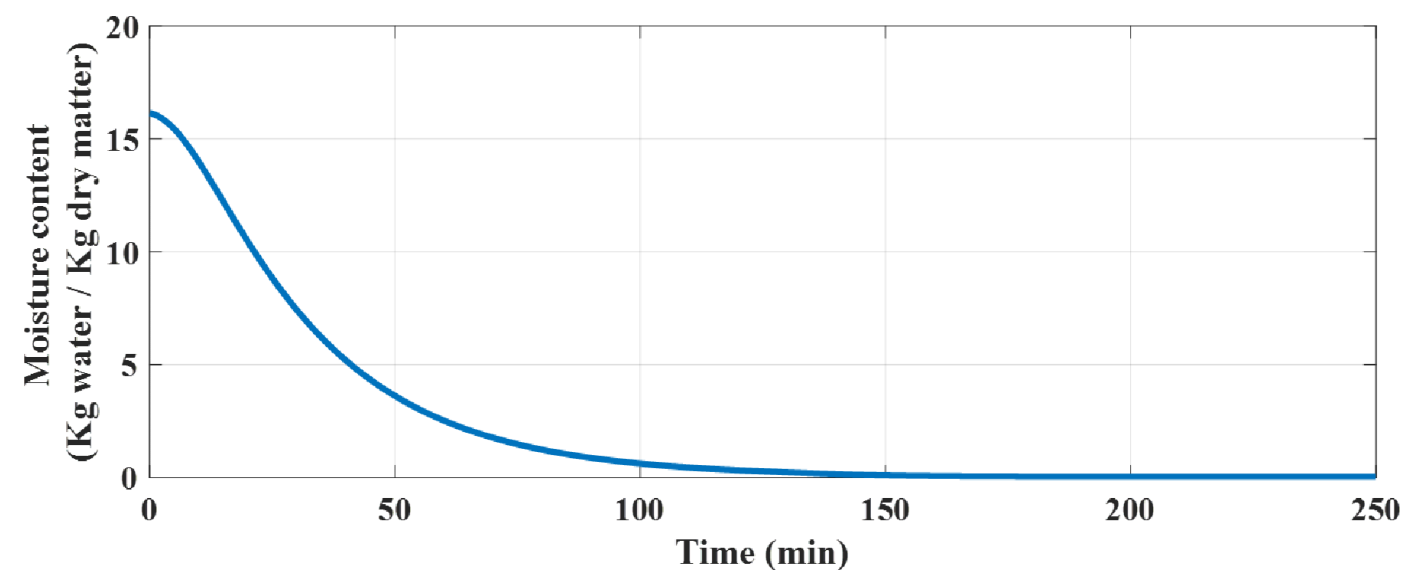

Figure 16.

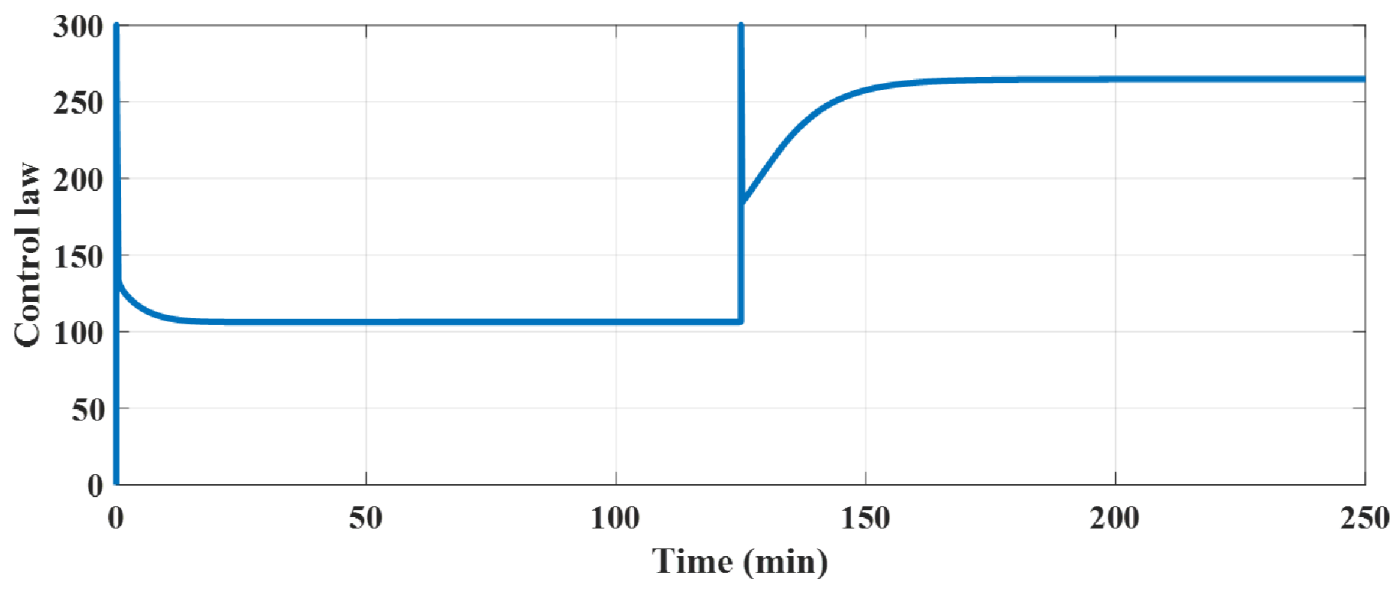

Figure 17.

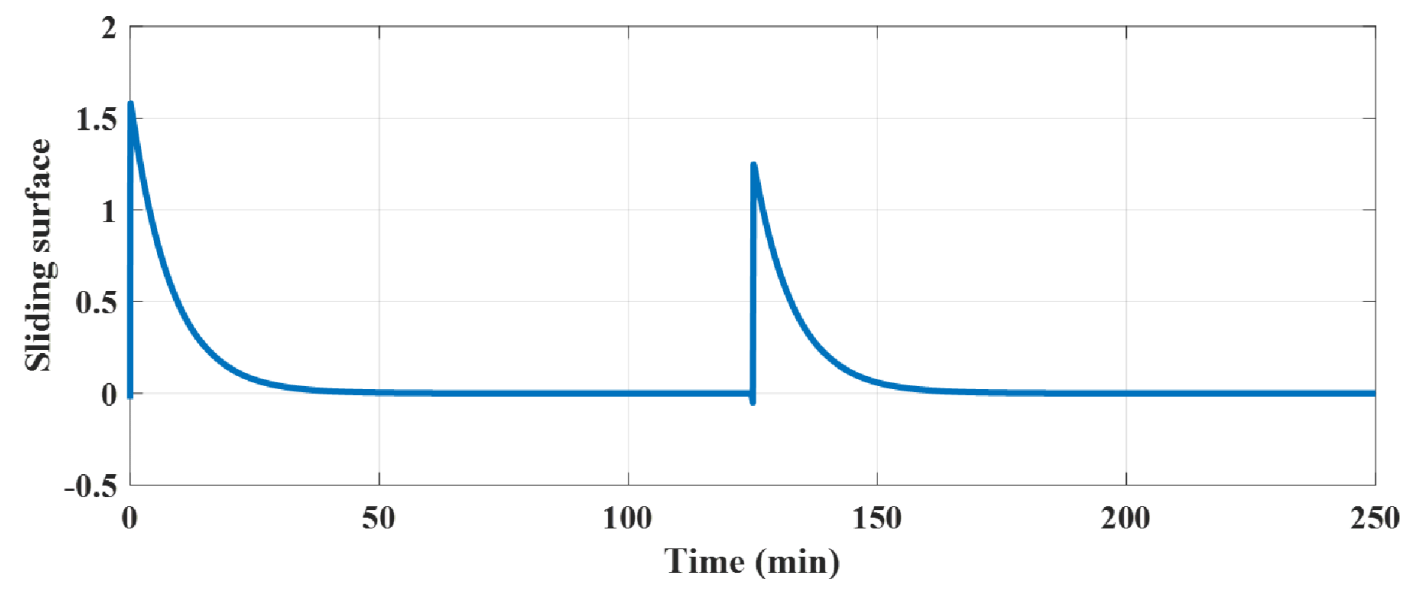


International Journal of System Dynamics Applications

Volume 10 •Issue 4

Figure 18.

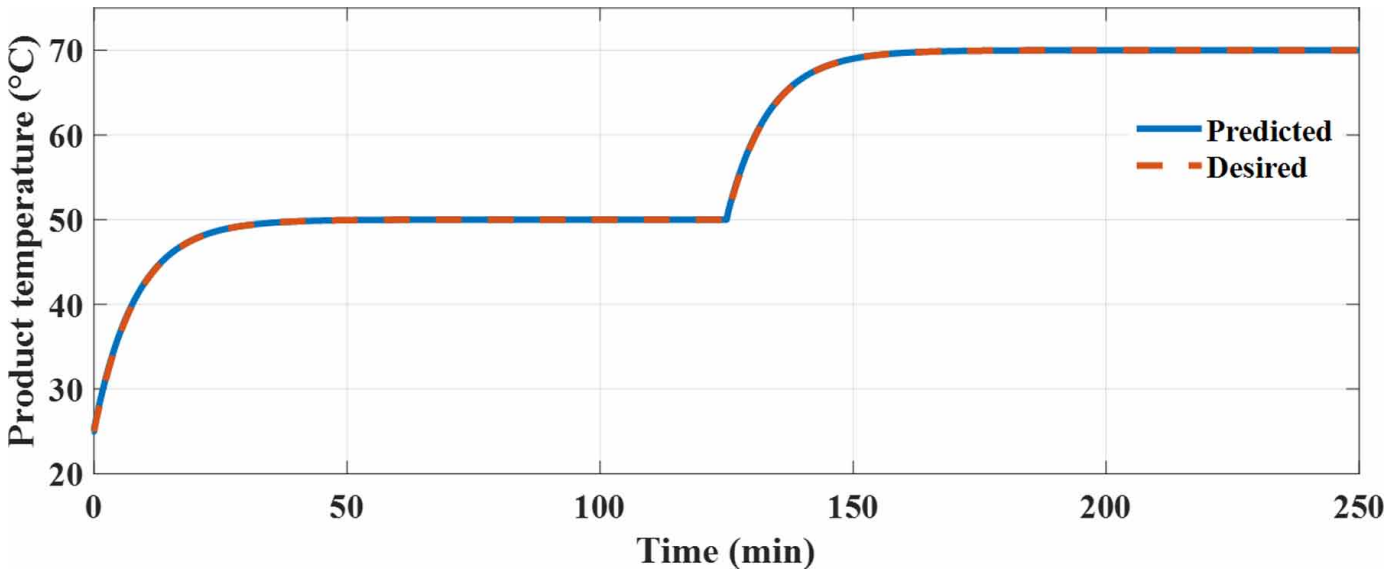

Figure 19.

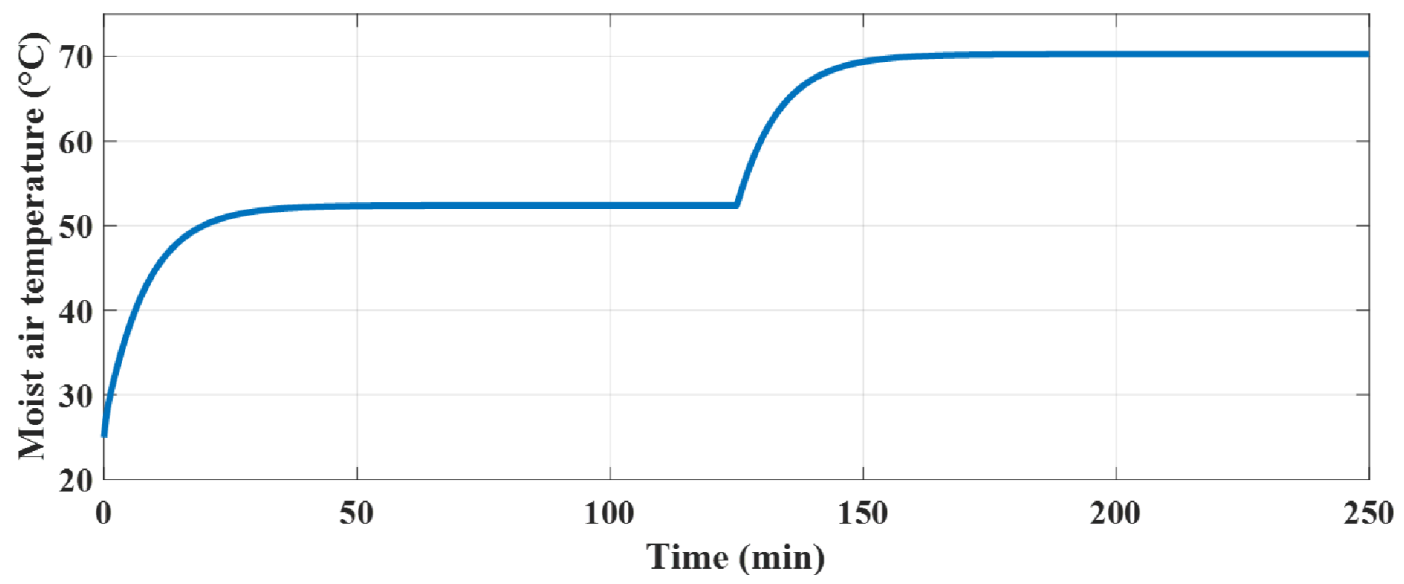

Figure 20.

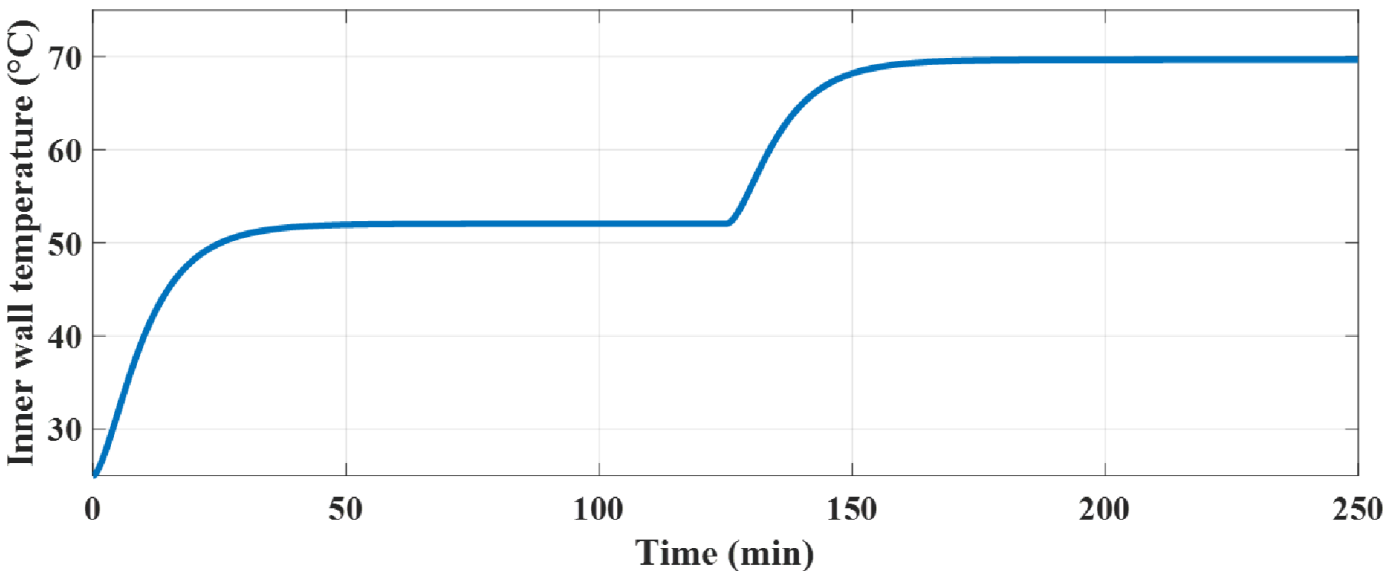


Figure 21.

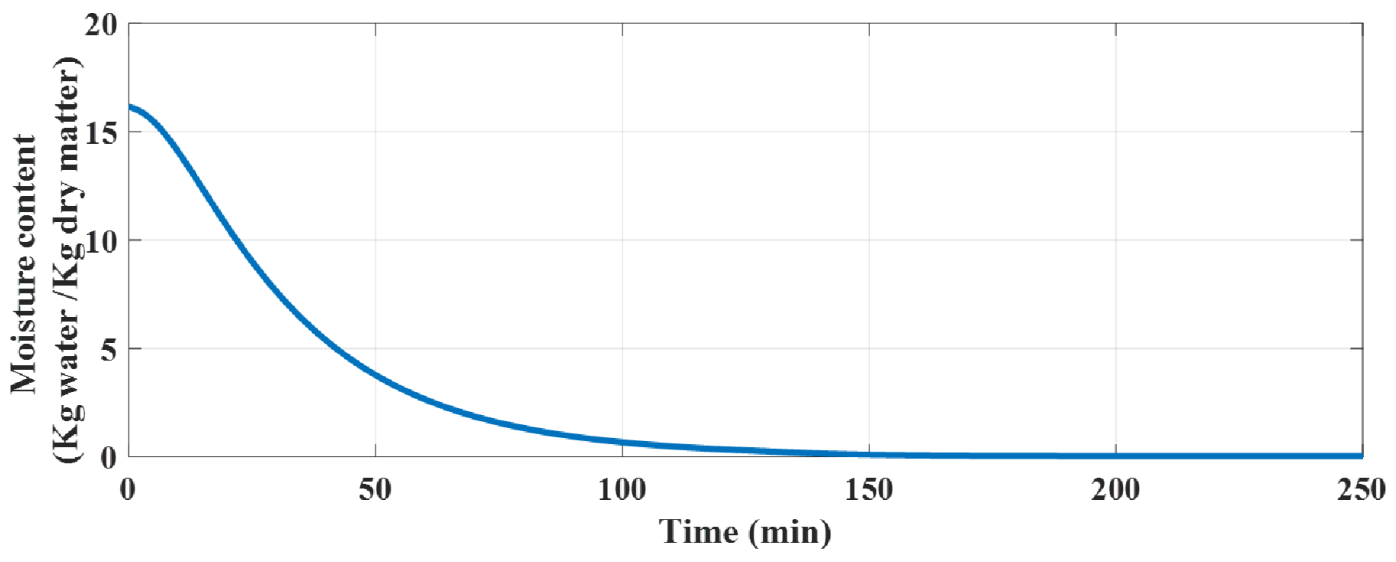

Likewise, there is no variation in the evolution of the curves of the control law and the sliding surface (Figures. 22 and 23).

Figure 22.

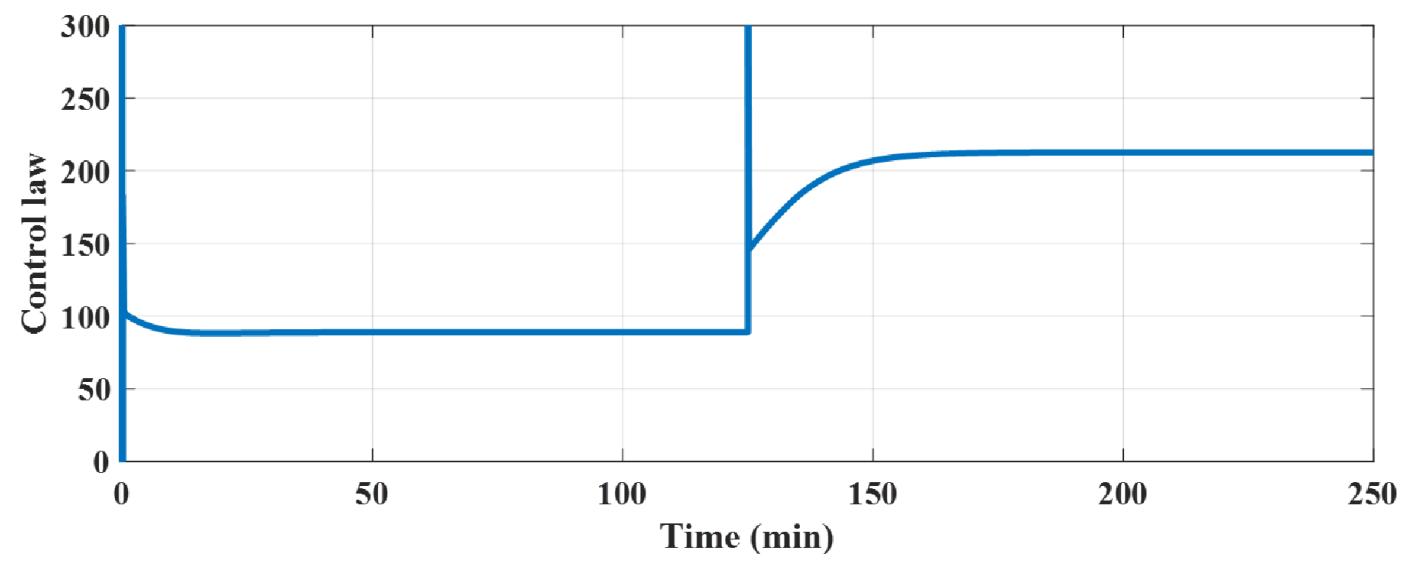

The system will keep these performances and is not affected by the parametric variations, this proves the robustness of the sliding mode control. It is obvious that the second designed sliding mode controllers in this paper can obtain the acceptable control performance.

Finally, both control strategies result in acceptable performance of the time varying system in tracking of various desired objectives. However, using the second conceived sliding mode controller leads to more smooth and quick time responses and without static error.

\section{CONCLUSION}

Convection drying using solar-gas hybrid dryers is considered a simple and less expensive method, most often used to extend the shelf life of food products. 
Figure 23.

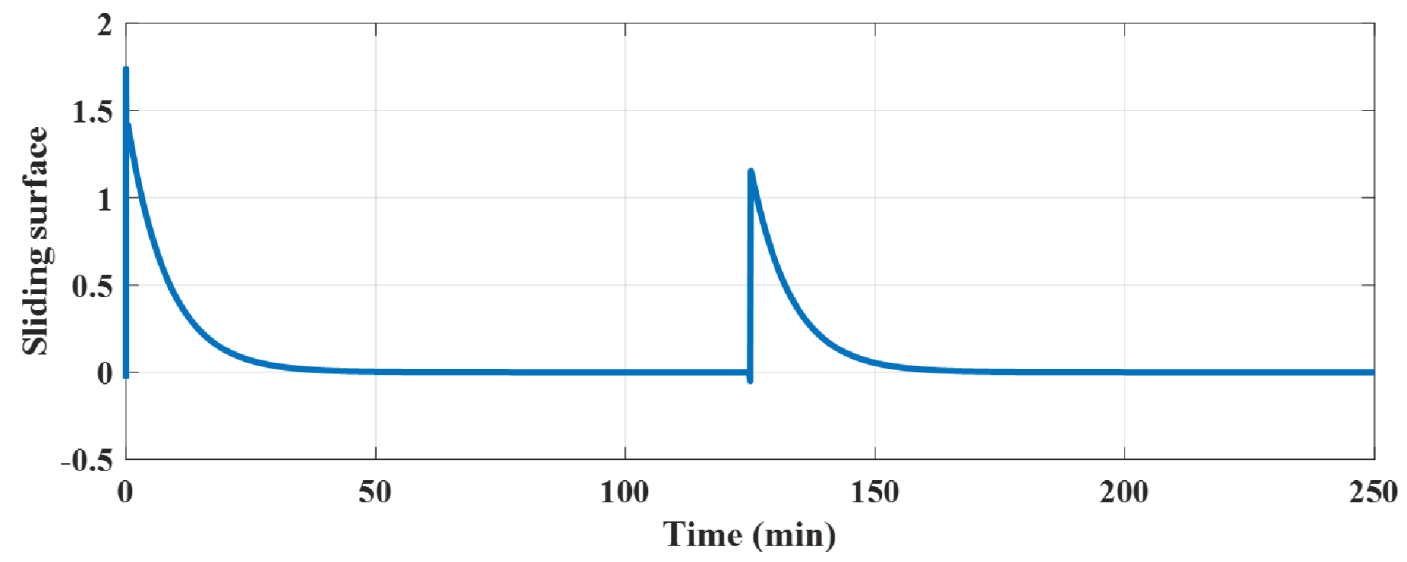

The excess production of tomatoes during the harvest period and in Mediterranean countries makes it possible to think about their conservation using various drying techniques.

The one used in this work is based on the study of the influence of the variation in the temperature of the drying air on various parameters such as the temperature and the moisture content of the product, which allows us to determine the best conditions for drying slices of tomato.

In this paper a developed mathematical model relate to the studied system has been used and an application of sliding mode control has been processed to analyse and optimize the operation mode of tunnel dryer.

First order sliding mode control was developed and tested by simulation on a tunnel dryer, to reduce the static error and the chattering phenomena which make the system inaccurate and which could represent some imperfections in real applications, a PI sliding surface had been developed and simulated. This last approach shows very effective qualities of control and robustness especially in term of the good tracking of trajectory and the reducing of chattering problem.

The presented design methodology of sliding mode control can also be applied to other nonlinear multi-variable dynamic systems. Moreover, others form of sliding surfaces need to be further investigated in future research.

\section{ACKNOWLEDGMENT}

This work was supported in part by Thermal Process Laboratory, Research and Technology Centre of Energy (CRTEn) and in part by the Tunisian Ministry of High Education and Scientific Research. 


\section{REFERENCES}

Abdel-Jabbar, N., Jumah, R., \& Al-Haj Ali, M. (2005). State Estimation and State Feedback Control for Continuous Fluidised Bed Dryers. Journal of Food Engineering, 70(2), 197-203. doi:10.1016/j.jfoodeng.2004.09.026

Aghbashlo, M., Sotudeh-Gharebagh, R., Zarghami, R., Mujumdar, A., \& Mostoufi, N. (2014). Measurement Techniques to Monitor and Control Fluidization Quality in Fluidized Bed Dryers: A Review. Drying Technology, 32(9), 1005-1051. doi:10.1080/07373937.2014.899250

Amer, B. M. A., Hossain, M. A., \& Gottschalk, K. (2010). Design and performance evaluation of a new hybrid solar dryer for banana. Energy Conversion and Management, 51(1), 813-820. doi:10.1016/j.enconman.2009.11.016

Andreas, B., Carsten, S., Robert, D., \& Christoph, N. (2018). Robust feedback control of convective drying of particulate solids. Journal of Process Control, 69, 86-96. doi:10.1016/j.jprocont.2018.07.010

Atthajariyakul, S., \& Leephakpreeda, T. (2006). Fluidized Bed Paddy Drying in Optimal Conditions via Adaptive Fuzzy Logic Control. Journal of Food Engineering, 75(1), 104-114. doi:10.1016/j.jfoodeng.2005.03.055

Bala, B. K., Mondol, M. R. A., Biswas, B. K., Das Chowdury, B. L., \& Janjai, S. (2003). Solar drying of pineapple using solar tunnel dryer. Renewable Energy, 28(2), 183-190. doi:10.1016/S0960-1481(02)00034-4

Delprat, S., \& Ferreira, D. L. A. (2012). High order sliding mode control for hybrid vehicle Stability. International Journal of Systems Science, 45(5), 1202-1212. doi:10.1080/00207721.2012.745241

Dinghua, H. X., Meibao, B. G., \& Haili, L. Z. (2013). Numerical solution of a dynamic model of heat and moisture transfer in porous fabric under low temperature. International Journal of Heat and Mass Transfer, 61(1), $149-157$.

Ehsan, G. G., \& Nikbakhsh, J. (2018). A System Dynamics Model for Studying the Policies of Improvement of Chicken Industry Supply Chain. International Journal of System Dynamics Applications, 7(4), 20-37. doi:10.4018/IJSDA.2018100102

Emelyanov, S. V., Korovin, S. V., \& Levantovsky, L. V. (1986). Higher Order Sliding Modes in the Binary Control System. Soviet Physics., 31(4), 291-293.

Fionn, M. G., Andrew, H., Enrico, F., \& Andy, S. (2014). Conditions affecting the moisture buffering measurement performed on compressed earth blocks. Building and Environment, 75(1), 11-18.

Floquet, T., Barbot, J. P., \& Perruquetti, W. (2003). Higher order sliding mode stabilization for a class of nonholonomic perturbed systems. Automatica, 39(6), 1077-1083. doi:10.1016/S0005-1098(03)00076-1

Gao, W., \& Hung, J. C. (1993). Variable structure control of nonlinear systems: A new approach. IEEE Transactions on Industrial Electronics, 40(1), 45-55. doi:10.1109/41.184820

Gianini, R. L., Wagner, A. D. S. C., Luiz, M. D. M. J., Paulo, R. P., \& Cid, M. G. A. (2010). Dynamic modeling and control of soybean meal drying in a direct rotary dryer. Food and Bioproducts Processing, 88(2-3), 90-98.

Goyal, R. K., \& Tiwari, G. N. (1997). Parametric study of a reverse flat plate absorber cabinet dryer: A new concept. Solar Energy, 60(1), 41-48. doi:10.1016/S0038-092X(96)00144-2

Hatem, O., Salah, B. M., \& Abdelkader, M. (2012). System Design, Mathematical Modelling and Simulation of Process Drying in a Solar-Gas Convective Tunnel Dryer. International Journal of Scientific and Engineering Research, 3(5), 1303-1310.

Hatem, O., Salah, B. M., \& Abdelkader, M. (2014). Design and Installation of a Solar-Gas Tunnel Dryer: Comparative Experimental Study of Two Scenarios of Drying. The Fifth International Renewable Energy Congress IREC, Hammamet, Tunisia.

Hatem, O., Salah, B. M., \& Abdelkader, M. (2014). Dynamic modelling and performance study of solar gas tunnel dryer. Mathematical and Computer Modelling of Dynamical Systems, 20(2), 130-145. doi:10.1080/13 873954.2013.819020

Hebertt, S. R. (2003). On the generalized PI sliding mode control of DC-to-DC power converters: A tutorial. International Journal of Control, 76(9-10), 1018-1033. doi:10.1080/0020717031000099047 
Hossain, M. A., \& Bala, B. K. (2007). Drying of hot chilli using solar tunnel dryer. Solar Energy, 81(1), 85-92. doi:10.1016/j.solener.2006.06.008

Hung, J. Y., Gao, W., \& Hung, J. C. (1993). Variable Structure Control: A Survey. IEEE Transactions on Industrial Electronics, 40(1), 2-21. doi:10.1109/41.184817

İlyas, E. (2006). Sliding mode control with PID sliding surface and experimental application to an electromechanical plant. [PubMed]. ISA Transactions, 45(1), 109-118. doi:10.1016/S0019-0578(07)60070-6

Isdore, P. G., Agnes, S. R., \& Benedict, O. (2018). Food Security Indicators for Subsistence Farmers Sustainability: A System Dynamics Approach. International Journal of System Dynamics Applications, 7(1), 45-64. doi:10.4018/ IJSDA.2018010103

Jain, D., \& Tiwari, G. N. (2004). Effect of greenhouse on crop drying under natural and forced convection II. Thermal modelling and experimental validation. Energy Conversion and Management, 45(17), 2777-2793. doi:10.1016/j.enconman.2003.12.011

Jalel, G., Ahmed, R., \& Sundarapandian, V. (2018). Discrete Time Sliding Mode Control Scheme for Nonlinear Systems With Bounded Uncertainties. International Journal of System Dynamics Applications, 7(2), 15-33. doi:10.4018/IJSDA.2018040102

Jekayinfa, S. O., \& Bamgboye, A. I. (2006). Estimating energy requirement in cashew (Anacardium occidentale L.) nut processing operations. Energy, 31(8-9), 1305-1320. doi:10.1016/j.energy.2005.07.001

Karnopp, D., Margolis, D., \& Rosenberg, R. (1990). System Dynamics: A Unified Approach. John Wiley \& Son Inc.

Khatchatourian, O. A., Vielmo, H. A., \& Bortolaia, L. A. (2013). Modelling and simulation of cross flow grain dryers. Biosystems Engineering, 116(4), 335-345. doi:10.1016/j.biosystemseng.2013.09.001

Lars, N. P., Niels, K. P., Hans, H. N., Christer, U., \& John, B. J. (2017). Comparison of three control strategies for optimization of spray dryer operation. Journal of Process Control, 57, 1-14. doi:10.1016/j.jprocont.2017.05.008

Lewis, W. K. (1921). The rate of drying of solid materials. Journal of Industrial and Engineering Chemistry, 13(5), 427-432. doi:10.1021/ie50137a021

Lokukaluge, P. P., \& Soares, C. G. (2012). Pre-filtered sliding mode control for nonlinear ship steering associated with disturbances. Ocean Engineering, 51(1), 49-62.

Lopez, A., Iguaz, A., Esnoz, A., \& Virseda, P. (2000). Modelling of sorption isotherms of dried vegetable wastes from wholesale market. Drying Technology, 18(4\&5), 995-1006. doi:10.1080/07373930008917749

Luciandra, M. T., Thayná, B. F., \& Mateus, J. R. P. (2018). Modelling the Dynamics of Cow-Calf Dyadic Behavior. International Journal of System Dynamics Applications, 7(4), 1-19. doi:10.4018/IJSDA.2018100101

Marcel, H., \& Ron, V. (2014). Self-tuning in integral sliding mode control with a Levenberg-Marquardt algorithm. Mechatronics, 24(4), 385-393. doi:10.1016/j.mechatronics.2013.05.005

Marco, T. A., Leonid, F., \& Arie, L. (2011). Robust exact finite-time output based control using high-order sliding modes. International Journal of Systems Science, 42(11), 1847-1857. doi:10.1080/00207721.2011.564676

Maya, F., Wataru, M., Keiichi, K., Tadashi, I., Kazunari, Y., \& Kazuhiro, S. (2014). Proportional control of moisture content of granules by adjusting inlet air temperature in fluidized bed granulation using near-infrared spectroscopy. Advanced Powder Technology, 25(2), 704-709. doi:10.1016/j.apt.2013.10.013

Mercier, S., Marcos, B., Moresoli, C., Mondor, M., \& Villeneuve, S. (2014). Modeling of internal moisture transport during durum wheat pasta drying. Journal of Food Engineering, 124(1), 19-27. doi:10.1016/j. jfoodeng.2013.09.028

Mohajer, A., Nematollahi, O., Joybari, M. M., Hashemi, S. A., \& Assari, M. R. (2013). Experimental investigation of a Hybrid Solar Dryer and Water Heater System. Energy Conversion and Management, 76(1), 935-944. doi:10.1016/j.enconman.2013.08.047

Mounir, D., Ahmad, T. A., Saïd, D., \& Driss, M. (2018). Higher Order Sliding Mode Control for Blood Glucose Regulation of Type 1 Diabetic Patients. International Journal of System Dynamics Applications, 7(1), 65-84. doi:10.4018/IJSDA.2018010104 
Musen, X., Jianxiong, Z., \& Wansheng, T. (2014). Optimal temperature control for quality of perishable foods. [PubMed]. ISA Transactions, 53(2), 542-546. doi:10.1016/j.isatra.2013.12.011

Nabanita, A., \& Chitralekha, M. (2013). integral backstepping sliding mode control for underactuated systems: Swing-up and stabilization of the Cart-Pendulum System. [PubMed]. ISA Transactions, 52(6), 870-880. doi:10.1016/j.isatra.2013.07.012

Naghavi, Z., Moheb, A., \& Ziaei-rad, S. (2010). Numerical simulation of rough rice drying in a deep-bed dryer using non-equilibrium model. Energy Conversion and Management, 51(1), 258-264. doi:10.1016/j. enconman.2009.09.019

Nawshad, H., \& Michael, S. (2013). Techno-Economic and Environmental Evaluation of Biomass Dryer. Procedia Engineering, 56(1), 650-655.

Pallet, D., Fournier, M., \& Themelin, A. (1987). Modélisation, identification et simulation d'un séchoir solaire à bois. Revue de Physique Appliquée (Paris), 22(1), 1399-1409. doi:10.1051/rphysap:0198700220110139900

Paul, M., Caroline, V., Claude D \& François, B. (2008). Influence of drying temperature on the solubility, the purity of isolates and the electrophoretic patterns of corn proteins. Food Chemistry, 111(3, 1), 564-572.

Pichardo, C., \& Delgado, M. (2003). Pseudo bond graph model and simulation of an industrial flash separator. Simulation Modelling Practice and Theory, 11(2), 125-150. doi:10.1016/S1569-190X(03)00011-X

Pkez-Correa, J. R., Cubillos, F., Zavala, E., Shene, C., \& Alvarez, P. I. (1998). Dynamic simulation and control of direct rotary dryers. Food Control, 9(4), 195-203. doi:10.1016/S0956-7135(97)00077-7

Robert, D., Carsten, S., Christoph, N., \& Andreas, B. (2019). Self-tuning control of continuous fluidized bed

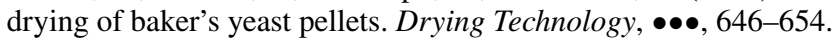

Rodriguez, G., Vasseur, J., \& Courtois, F. (1996). Design and Control of Drum Dryers for the Food Industry. Journal of Food Engineering, 30(1-2), 171-183. doi:10.1016/0260-8774(95)00054-2

Salah, B. M., \& Ali, B. (1994). Simulation and design of a tunnel dryer. Renewable Energy, 5(1-4), 469-473. doi:10.1016/0960-1481(94)90416-2

Salah, B. M., Elaid, B., \& Hatem, O. (2012). Experimental study and numerical modelling of drying characteristics of apple slices. Food and Bioproducts Processing, 90(4), 719-728. doi:10.1016/j.fbp.2012.02.001

Salah, L., Franck, P., \& Alain, G. (2007). Higher order sliding mode control based on integral sliding mode. Automatica, 43(3), 531-537. doi:10.1016/j.automatica.2006.09.017

Sana, B., \& Anis, S. (2018). Adaptive Neuro-Fuzzy Sliding Mode Controller. International Journal of System Dynamics Applications, 7(2), 34-54. doi:10.4018/IJSDA.2018040103

Sara, D., \& Hamid, R. M. (2013). Passivity-based fractional-order integral sliding mode control design for uncertain fractional-order nonlinear systems. Mechatronics, 23(7), 880-887. doi:10.1016/j.mechatronics.2013.05.009

Slotine, J. J., \& Li, W. (1991). Applied Nonlinear Control. Prentice-Hall.

Temple, S., \& van Boxtel, A. (2000). Control of Fluid Bed Tea Dryers: Controller Design and Tuning. Computers and Electronics in Agriculture, 29, 209-216. doi:10.1016/S0168-1699(00)00149-6

Utkin, V. (1977). Variable structure systems with sliding modes. IEEE Transactions on Automatic Control, 2(22), 212-222. doi:10.1109/TAC.1977.1101446

Van Engeland, C., Spreutels, L., Legros, R., \& Haut, B. (2019). Convective Drying of Baker's Yeast Pellets Containing a Carrier. Drying Technology, 37(11), 1405-1417. doi:10.1080/07373937.2018.1504060

Vidaña, E. C. L., Lagunas, L. L. M., \& Ramírez, J. R. (2013). Efficiency of a hybrid solar-gas dryer. Solar Energy, 93(1), 23-31. doi:10.1016/j.solener.2013.01.027

Vieira, G., Olazar, M., Freire, J., \& Freire, F. (2019). Real-Time Monitoring of Milk Powder Moisture Content during Drying in a Spouted Bed Dryer Using a Hybrid Neural Soft Sensor. Drying Technology, 37(9), 1184-1190. doi:10.1080/07373937.2018.1492614 
Villegas, J. A., Duncan, S. R., Wang, H. G., Yang, W. Q., \& Raghavan, R. S. (2009). Distributed Parameter Control of a Batch Fluidized Bed Dryer. Control Engineering Practice, 17(9), 1096-1106. doi:10.1016/j. conengprac.2009.04.012

Zolezzi, T. (2004). A variational approach to second order approximability of sliding mode control systems. Optimization, 53(5-6), 641-654. doi:10.1080/0233193042000327100 


\section{APPENDIX A}

The convective heat transfer coefficient between the hot air and the agricultural product has been expressed as:

$$
h_{c 1}=h_{c 2}=N u \frac{\lambda_{a}}{D}
$$

$\mathrm{Nu}$ is the number of Nusselt established on the basis of Reynolds number (Re) (Pallet, Fournier \& Themelin, 1987):

$$
N u=0.023 \cdot \operatorname{Re}^{0.8} \cdot \operatorname{Pr}^{0.4}
$$

The Reynolds number is expressed as:

$$
\operatorname{Re}=\frac{U_{a} l}{v}
$$

The convective heat transfer coefficient between the moist air and the inner wall $h_{c 3}$ is calculated using another expression of Nusselt number (Pallet, Fournier \& Themelin, 1987):

$$
N u=0.036 \cdot \operatorname{Re}^{4 / 5} \cdot \operatorname{Pr}^{1 / 3}
$$

The conductive heat-transfer coefficient across the insulation is estimated by:

$$
h_{d}=\frac{\lambda_{i}}{d_{i}}
$$

The evaporative heat transfer coefficient is given by Jain and Tiwari Goyal \& Tiwari, 1997):

$$
h_{\text {evap }}=0.016 h_{c} \frac{\left[P\left(T_{p r}\right)-\gamma_{c h} P\left(T_{c h}\right)\right]}{\left(T_{p r}-T_{c h}\right)}
$$

$\Delta P$ and $\Delta H$ are the difference in partial pressure and the difference in pressure head $(m)$ respectively (Jain \& Tiwari, 2004) and expressed as:

$$
\Delta P=\left[P\left(T_{c h}\right)-\gamma_{e x} P\left(T_{e x}\right)\right]
$$


International Journal of System Dynamics Applications Volume 10 - Issue 4

$$
\Delta H=\frac{\Delta P}{\rho_{a} g}
$$




\section{APPENDIX B}

\section{Table 3. Nomenclature}

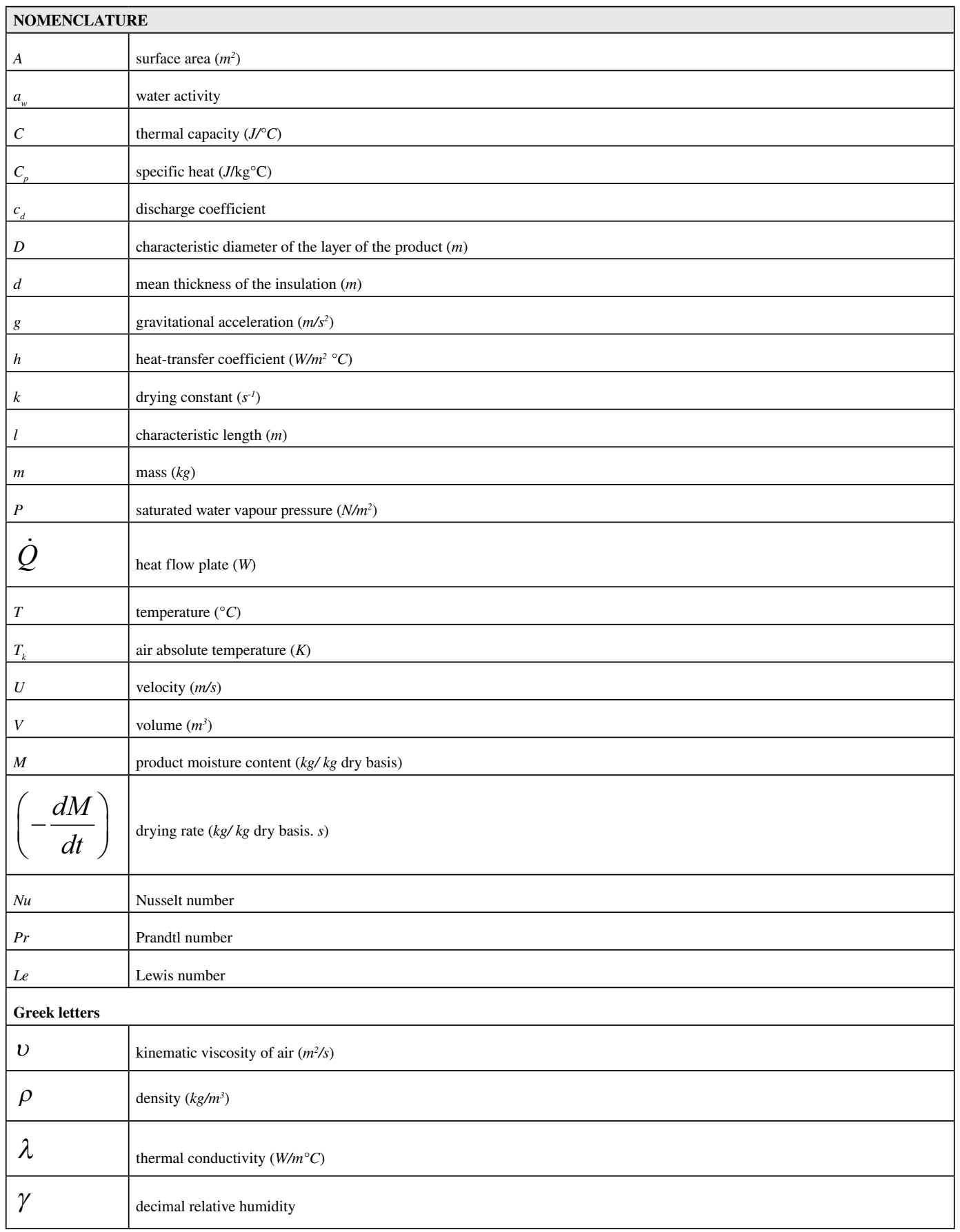


Table 3. Continued

\begin{tabular}{|l|l|}
\hline \multicolumn{2}{|l|}{ NOMENCLATURE } \\
\hline \multicolumn{2}{|l|}{ Subscripts } \\
\hline$a$ & air \\
\hline$c$ & convection \\
\hline$d$ & conduction \\
\hline$e$ & equilibrium \\
\hline$i$ & insulation \\
\hline$c h$ & moist air in the chamber \\
\hline evap & evaporation \\
\hline evac & evacuation \\
\hline$p r$ & product \\
\hline$h a$ & hot air \\
\hline$w a$ & wall \\
\hline
\end{tabular}

Hatem Oueslati received his Ph.D. in Electrical Engineering (2013) from the National Engineering School of Tunis (ENIT) in Tunisia, University of Tunis el Manar. Currently he is a Researcher at the Research and Technologies Center of Energy in Borj Cedria-Tunisia. His main research areas and activities are based on the Modeling and Control of Thermal Processes and the Feasibility Analysis of Energetic Systems Based on Renewable Sources.

Salah Ben Mabrouk received his Ph.D. in Mechanical Engineering and Thermal Buildings (1984) from the University of Poitiers (France) and Doctorate Degrees Thesis in Sciences Physics (These d'Etat Es- Sciences Physics) at the Faculty of Sciences of Tunis (1999), University of Tunis el Manar. He is currently a Professor in Physics and Mechanical Engineering at the Research and Technologies Center of Energy in Borj Cedria-Tunisia and Head of national and international projects concerning the Solar Drying Processes and Renewable Energy Applications.

Abdelkader Mami received his Ph.D. and Doctorate in Electrical Engineering, from University of Aix Marseille (France) and University of Sciences and Technologies of Lille (France) in 1992 and 2003, respectively. He is currently a Professor of Electrical Engineering at the Faculty of Sciences of Tunis (FST) and the Director of the Laboratory of the Energy Efficiency and Renewable Energies Application (LAPER). 